\title{
The development of geophysics in the early period of the People's Republic of China based on the Institute of Geophysics, Chinese Academy of Sciences (1950-1966)
}

\author{
Zhihui Zhang ${ }^{1,2}$ and Rui Wang ${ }^{1,3}$ \\ ${ }^{1}$ Institute for the History of Natural Sciences, Chinese Academy of Sciences, Beijing, 100190, PR China \\ ${ }^{2}$ Post-doctoral research station, China Three Gorges Corporation, Beijing, 100038, PR China \\ ${ }^{3}$ University of Chinese Academy of Sciences, Beijing, 100049, PR China \\ Correspondence: Zhihui Zhang (zhangzhihui1008@163.com)
}

Received: 17 February 2020 - Revised: 8 November 2020 - Accepted: 14 December 2020 - Published: 3 February 2021

\begin{abstract}
From the perspective of the social history of science and transnational history, this paper reviewed the development of the Institute of Geophysics, Chinese Academy of Sciences (IGCAS), rather than focusing on its scientific achievements. Before the 1950s, the discipline of geophysics in China, except for the branch of meteorology, had a very weak foundation, and few researchers were engaged in it. The systematic development of geophysics began with the establishment of IGCAS. In this paper, the early development of IGCAS was researched thoroughly. At first, we briefly reviewed the establishment process for IGCAS. After being promoted by the desire of scientists to develop big geophysics, the Chinese Academy of Sciences (CAS) integrated scattered academic forces, which included geomagnetism and geophysical exploration, to establish the IGCAS. The IGCAS was based on the Institute of Meteorology of Academia Sinica in the Republic of China era. After that, we summarized work done by IGCAS in the development of geophysics from the 1950s to 1966, the year in which the Cultural Revolution began. We focused on policy support, adjustment of organizational structure, and scientific capacity building, when China was facing an isolated international diplomatic environment, continuous domestic political movements, and an austere social economy. Then, to bolster the development of geophysics in China, the slogan of "Missions Drive Disciplines", which was instilled and implemented by the Chinese scientific community, was introduced briefly. The scientific development of the IGCAS and typical examples in several branches of geophysics, which included atmospheric science, seismology, space physics, and other fields, were systematically summarized and benchmarked to the international academic level. We then summarized the basic research on geophysics carried out by the institute in economic construction and national defense. Finally, the experience and lessons in the development of this institute and its effect on geophysics in China were explored.
\end{abstract}

\section{Introduction}

After the Second Sino-Japanese War (1937-1945) and the long-term civil war between the Kuomintang and the Communist Party (1945-1949), China's national economy became very weak, and its scientific and technological foundation was on an awkward footing. The Communist Party of China took over in October 1949 and established the People's Republic of China (PRC). To develop science and technology rapidly, just a month later, the Communist Party of China established the Chinese Academy of Sciences (CAS) that followed the Russian example and tried to build it into a locomotive of national scientific and technological strength. The Korean War began in 1950, which caused the new regime to face economic sanctions and a blockade of scientific and technological exchanges. From the very beginning, China's science and technology community was entrusted with the mission of promoting the development of the national econ- 
omy. This was especially true of the CAS and its research institutes.

The institutes under CAS were entrusted by the state with the mission of serving national economic construction and military needs. The Institute of Geophysics, Chinese Academy of Sciences (hereinafter IGCAS) was the home for geophysics in contemporary China.

Between the 1950s and 1970s, "missions drive disciplines; discipline promotes mission" was the slogan put forward to deal with the relationship between missions and disciplines. Scientific research was expected to follow the law, but at that time, a large number of scientists had to engage in a great deal of applied work, which included national economic construction and national defense missions. In a difficult situation during several political movements, the institute attempted to provide significant support for the development of geophysics (e.g., technical capacity, talent reserve, and policy support). However, in the early years of the PRC, even though geophysics was still dominated by observational and qualitative research, IGCAS made some scientific achievements.

Most of the existing literature on the early development of the institute was found in the memoirs of scientists; however, there was still a lack of in-depth research on the features of the development of geophysics in China and its scientific achievement in different subdisciplines of geophysics. Our focus in this paper was based on original archives, the memoirs of scientists, and secondary sources in order to explore the development of geophysics in China.

Compared with their western counterparts, in the first 20 years of socialist PRC, Chinese geophysicists did not achieve many world-class results due to complex historical reasons that included the Cold War, the neglect of basic science, and eagerness for rapid success in economic development. However, this paper will be a window into the history of the development of geophysics in modern China.

\section{Origin, establishment, and particular details of IGCAS}

Geophysics, which is a borderline science between geoscience and physics, was introduced to China in the late Qing dynasty during the early days of the Republic of China when Jesuits controlled the country or controlled science. It was the earliest natural science discipline introduced to China. Modern Western meteorological observation technology was also introduced at the same time by the missionaries. Being located near Shanghai, the Sheshan geomagnetic station was first established by the French in Shanghai and began to collect data officially in 1887. It was the earliest geomagnetic station in China and one of the oldest in the world. The central observatory that was created in 1912 by the Ministry of Education accumulated comparatively rich observations. Not until the 1920s, when the Academia Sinica and the Institute of Physics of the National Academy of Peiping were established, did geophysics become a research direction and a formal discipline and begin to receive the attention of physicists. On 1 January 1929, the National Research Institute of Meteorology of Academia Sinica (hereinafter referred to as the Institute of Meteorology) was established; Chinese meteorologist Kezhen Zhu assumed the position of the director. Very quickly, the institute became a famous meteorological observation and scientific research base in China, and different divisions, such as the weather group, meteorological observatory, meteorology group, instrument room, geomagnetic station, and seismology office, were developed. However, except for meteorology, which had an established foundation, the other branches of geophysics were extremely weak or even nonexistent. Work in seismology and geomagnetism was attached to the meteorological observatory or the astronomical observatory; research work in geophysics was limited to academic institutions and was rarely combined with production, and the business sector also did not attach importance to it. The excavation of natural resources, which included physical prospecting, was led by the Ministry of Geology and related production sectors (Jaw, 1957a, pp. 1-8).

Hardware facilities, such as observation stations, which was the technical support for geophysical observation, were developed piecemeal during the Republic of China period. In 1930, under the direction of Shanbang Li, the geophysics laboratory at the Geological Survey Institute of the Ministry of Industry and Commerce established the first independently constructed seismic station in China in the western suburbs of Peiping, which was named the Jiufeng Seismic Station, and it was world class at the time. In 1931, the Institute of Meteorology purchased a pair of Wiechert seismographs from Germany, added weather stations, and helped each province or municipality set up weather-monitoring stations to study the various types of weather in China. Xilin Ding, who directed the Institute of Physics at Academia Sinica, set up the Nanjing Zijinshan Geomagnetic Station in the 1930s, which was the first self-built geomagnetic station in China.

After World War II, the discipline of geophysics developed rapidly internationally. Jeou-jang Jaw and geomagnetic scientist Zongqi Chen actively integrated the scientific and technological strength of geophysics in China after the Second Sino-Japanese War. However, because the Chinese nationalist government did not attach importance to science, work could only be launched on a small scale. In 1947, the geomagnetic station at the Institute of Physics belonged to the Institute of Meteorology at Academia Sinica and was reorganized as the geomagnetic group, and Hong'e Chen established a geomagnetic station in Nanjing to quickly resume observational work. The Institute of Meteorology separately established the general geophysics group (Secretariat of the Central Office of Administration of Academia Sinica, 1988).

The Chinese Geophysical Society, which was a national society, convened its inaugural meeting in August 1947 in 
Shanghai (Chinese Geophysical Society, 2012, p. 70). In June 1948, the first issue of the Journal of the Chinese Geophysical Society was published in English to promote communication with international peers ( $\mathrm{Wu}, 2002)$.

Overall, during the period of the Chinese nationalist government, a modicum of academic strength was accumulated in the fields of geophysics, which included meteorology, seismology, geomagnetism, and physical prospecting, and a national academic society was established. Although the fields were scattered, expertise was weak, and few people were involved, geophysics was now rooted in China. It should be noted that, on the whole, geophysics at that time was mainly focused on phenomenological research in China and throughout the world.

On the eve on which the Kuomintang regime, led by Chiang Kai-shek, fled in defeat to Taiwan, the Institute of Meteorology received orders to move to Taiwan; Jeou-jang Jaw and Zongqi Chen refused to go to Taiwan. CAS was established on 1 November 1949, and the government administration council decided to establish IGCAS on 6 April 1950. The institute was formed by merging the meteorological and geomagnetic departments of the former Institute of Meteorology at Academia Sinica and the physical prospecting department of the Institute of Physics at the National Academy of Peiping. On 19 May 1950, Chinese premier Zhou Enlai appointed Jeou-jang Jaw as the director (Hu, 1994); the deputy directors were Zongqi Chen and Gongxu Gu, and there were 57 staff members. On 12 December 1950, IGCAS also took over the management of the seismological and geomagnetic departments of the Xujiahui Observatory and the Sheshan Astronomical Observatory in Shanghai, and the Geophysics Laboratory of the Central Geological Survey merged with IGCAS (Jaw, 1954). The location of the institute was temporarily in Nanjing, and it moved to Beijing at the end of 1954 (Chen, 1992a). In 1953, the Geophysical Society was rebuilt and attached to IGCAS. The society's office and the editorial board of the Journal of the Chinese Geophysical Society were both part of the IGCAS. The director of IGCAS, Jeou-jang Jaw, was elected as the first chairperson at the first annual meeting in 1957 (Qian, 1957).

IGCAS preserved all magnetic photos from 27 February 1877 to 31 February 1962, which totalled 353 sections (Gao and $\mathrm{Hu}, 1993$ ) and included records from Sheshan station.

\section{The history of cultivating talent, organizational structure, and development policy of IGCAS}

Under the leadership of the Communist Party of China, scientific research in China exhibited a strong bureaucratic system to strengthen its control over intellectuals and the development of science and technology. As an academic and administrative leader, the director of the research institute had the right to allocate resources. In the period of the planned economy from 1949 to 1978 , scientific research activity and personnel training were also carried out according to administrative planning. The scientific research layout and science and technology policy of an institution also had great influence on the development of specific disciplines. Under the influence of the idea of "missions drive disciplines", scientists engaged in a significant amount of scientific research that was closely related to the national economy or national defense but looked for opportunities related to basic scientific research. Scientific research displayed a strong practical orientation. It was rare to see the kind of free and exploratory basic research that was apparent in the West. Therefore, before exploring the contribution of top scientists who worked at the Institute of Geophysics at CAS to the development of geophysics as a discipline, this paper will explore the evolution of the scientific research agenda and related policies of the institute.

Different from the institutes under the Soviet Academy of Sciences and the Max Planck Society, CAS undertook the mission of leading research and practice. Actually, for a long time, CAS, as the highest academic organ of the state and the center of national scientific research, played an important part as a locomotive of science and technology under the call of marching into modern science (Jiang, 2015). The associated institutes at CAS played a similar role in their separate disciplines and research fields.

After its establishment in 1950, IGCAS experienced a golden period of development. As director, Jeou-jang Jaw proposed the three transformations policy. Socioeconomic development put forward urgent demands on the development of the discipline of geophysics. The institute continuously improved its organizational structure and attracted and cultivated talent through a variety of channels; it actively opened up a series of disciplines and fields, which laid the foundation for geophysics in China, and IGCAS became an academic center in China.

\subsection{The kinds of expertise brought into institutions and their scientific impact}

The top priority was to recruit and cultivate talent. Starting in the 1930s, some physics elites went to European countries to study geophysics. The earliest talents were trained as geophysicists at some of the world's top universities and research institutes in Europe and the United States, such as the Berlin University in Germany, McGill University in Canada, and the California Institute of Technology and the University of Chicago in the USA. After returning to China to work, they brought back expertise from different fields. With their talent and scientific research, they laid the foundation for the discipline of Chinese geophysics, and their scientific achievements raised the international reputation of Chinese geophysics.

Cultivating talent was the top priority for the development of the research institute. The foundation of meteorological sciences in the so-called new China was weak; Kezhen Zhu, 
Table 1. Scientists who were educated abroad and who worked at the IGCAS in the early years.

\begin{tabular}{|c|c|c|c|c|}
\hline No. & Trained overseas & Foreign institutions & $\begin{array}{l}\text { Expertise brought into } \\
\text { China }\end{array}$ & $\begin{array}{l}\text { Scientific achievements } \\
\text { in the second half of the } 20 \text { th century }\end{array}$ \\
\hline 1 & Jeou-jang Jaw & $\begin{array}{l}\text { University of Berlin, } \\
\text { Germany }\end{array}$ & Geophysics & $\begin{array}{l}\text { Dynamic meteorology and high-altitude meteo- } \\
\text { rology; ocean dynamics }\end{array}$ \\
\hline 2 & Zongzi Chen & $\begin{array}{l}\text { Institute of Geophysics, } \\
\text { Potsdam, Germany; } \\
\text { Imperial College, London, } \\
\text { UK }\end{array}$ & $\begin{array}{l}\text { Geomagnetism } \\
\text { Geomagnetism; geo- } \\
\text { physical prospecting }\end{array}$ & $\begin{array}{l}\text { Initially built the national geomagnetic } \\
\text { network. Compiled the geomagnetic map of } \\
\text { China (1950) }\end{array}$ \\
\hline 3 & Gongfu Gu & $\begin{array}{l}\text { Colorado School of Mines, } \\
\text { USA; Department of Earth } \\
\text { Sciences, California Insti- } \\
\text { tute of Technology, USA }\end{array}$ & $\begin{array}{l}\text { Geophysical explo- } \\
\text { ration and seismology }\end{array}$ & $\begin{array}{l}\text { Made unique contributions to the theory of seis- } \\
\text { mic body wave, surface wave, heat wave, seis- } \\
\text { mic ray, and seismic origin }\end{array}$ \\
\hline 4 & Chengyi Fu & $\begin{array}{l}\text { Colorado School of Mines, } \\
\text { California Institute of Tech- } \\
\text { nology, USA }\end{array}$ & $\begin{array}{l}\text { Seismic wave propaga- } \\
\text { tion theory }\end{array}$ & $\begin{array}{l}\text { Some problems about the propagation theory of } \\
\text { elastic wave and seismic prospecting }\end{array}$ \\
\hline 5 & Tu-cheng Yeh & $\begin{array}{l}\text { University of Chicago, } \\
\text { USA }\end{array}$ & Atmospheric science & Theory of long-wave energy dispersion \\
\hline 6 & Gangkun Zhu & $\begin{array}{l}\text { Department of Physics, } \\
\text { Oxford University, UK }\end{array}$ & $\begin{array}{l}\text { Tidal effect in } \\
\text { Geophysics }\end{array}$ & $\begin{array}{l}\text { Meteorology and climatology; geomagnetism } \\
\text { and high-altitude physics }\end{array}$ \\
\hline 7 & $\begin{array}{l}\text { Zhenchao Gu } \\
\text { (abandoned } \\
\text { his doctorate } \\
\text { in 1950) }\end{array}$ & $\begin{array}{l}\text { Stockholm University, } \\
\text { Sweden }\end{array}$ & Atmospheric science & $\begin{array}{l}\text { Based on the dynamic and thermal effects of the } \\
\text { Tibetan Plateau on the atmospheric circulation } \\
\text { in East Asia and the weather system in China }\end{array}$ \\
\hline 8 & Qingcun Zeng & $\begin{array}{l}\text { Academy of Sciences, } \\
\text { Russia (former } \\
\text { Soviet Union) }\end{array}$ & $\begin{array}{l}\text { Atmospheric dynamics, } \\
\text { hydrodynamics, numer- } \\
\text { ical weather forecasting } \\
\text { theory, etc. }\end{array}$ & $\begin{array}{l}\text { Initiated the semi-implicit difference method } \\
\text { and successfully realized the original equation } \\
\text { for numerical weather forecasting }\end{array}$ \\
\hline 9 & Xiuji Zhou & $\begin{array}{l}\text { Associate doctor in Applied } \\
\text { Geophysics, Academy } \\
\text { of Sciences, Russia (former } \\
\text { Soviet Union; 1956-1962) }\end{array}$ & Atmospheric physics & $\begin{array}{l}\text { Using statistical physics and stochastic process } \\
\text { theory methods, the theory of warm cloud pre- } \\
\text { cipitation fluctuation was systematically estab- } \\
\text { lished }\end{array}$ \\
\hline
\end{tabular}

Source: official website of the Geophysics Research Institute of the State Seismological Bureau.

Changwang Tu, and Jeou-jang Jaw fervently invited friends and students who were studying abroad to return to China. Zhenchao Gu was taking advanced studies at Stockholm University in Sweden; he did not complete the doctorate that he was about to attain, nor did he take the opportunity that he had to study in the United States, and he resolutely decided to return to China immediately. A group of meteorologists, which included Tu-cheng Yeh, also responded to the call and returned to China; many served as laboratory leaders at IGCAS, and many of them became pioneers in geophysics in China (see Table 1).

Jeou-jang Jaw, (often called Jiuzhang Zhao after 1958), was a famous Chinese atmospheric scientist, geophysicist and space physicist who became the founder of China's dynamic meteorology, an initiator and founder of China's satellite industry, and a pioneer of China's modern geophysi- cal science (Fig. 1). Jaw graduated from the Department of Physics at Tsinghua University in 1933. Then, he attended the University of Berlin with the help of a scholarship from the Boxer Indemnity. When in Germany, he assiduously studied dynamic meteorology and high-altitude meteorology under the guidance of Heinrich Von Ficker, learned ocean dynamics from Albert Defant (1884-1974), and obtained his doctorate in 1938. He later returned to China, where he became the director of the Institute of Geophysics, CAS, for 16 years (1950-1966).

When studying at the University of Berlin, Jaw completed a paper titled "Thermal dynamics in the mainstream" and published it in a professional German journal in 1937 (Jaw, 1937). This was the first paper on dynamic meteorology in China. At that time, H. Von Ficker used observations of the North Atlantic trade wind to draw a general inference 


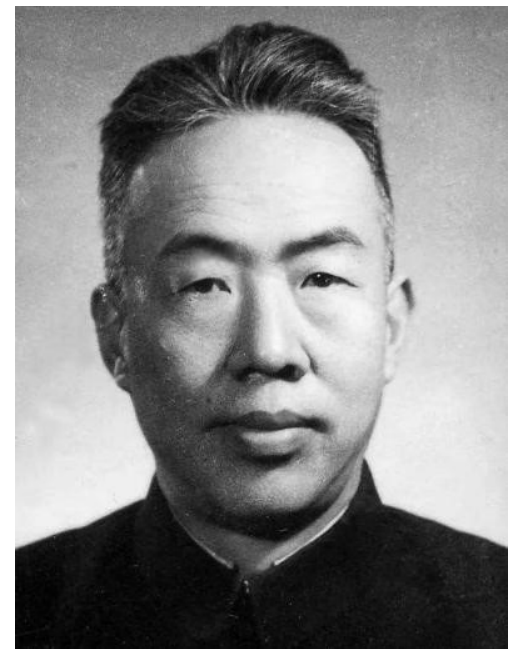

Figure 1. Jeou-jang Jaw (15 October 1907-26 October 1968). Source: courtesy of the Chinese Academy of Sciences.

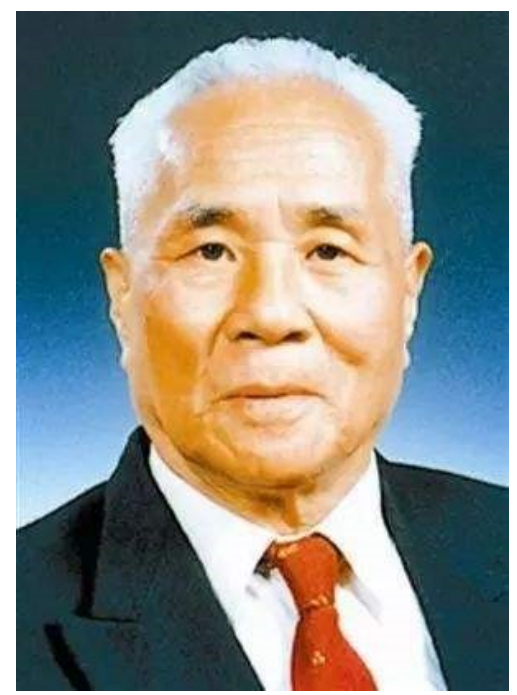

Figure 2. Chengyi Fu (7 October 1909-8 January 2000). Source: courtesy of the Chinese Academy of Sciences.

method and concluded that the energy stored in the trade wind mainstream per kilogram of air was $10 \mathrm{kcal}$. Jaw tried to verify Von Ficker's research by other methods. By using a particular physical law to deduce phenomena in the natural world, and by making comparisons between actual observations and theoretical calculations, he not only won the praise of Von Ficker and Defant, but also immediately brought international meteorology to the attention of the academic world. Kezhen Zhu, who was the founder of modern geography and meteorology in China, once evaluated this article as being "the most important achievement in theoretical meteorological research before the founding of the People's Republic of China" (Chen, 1992b).

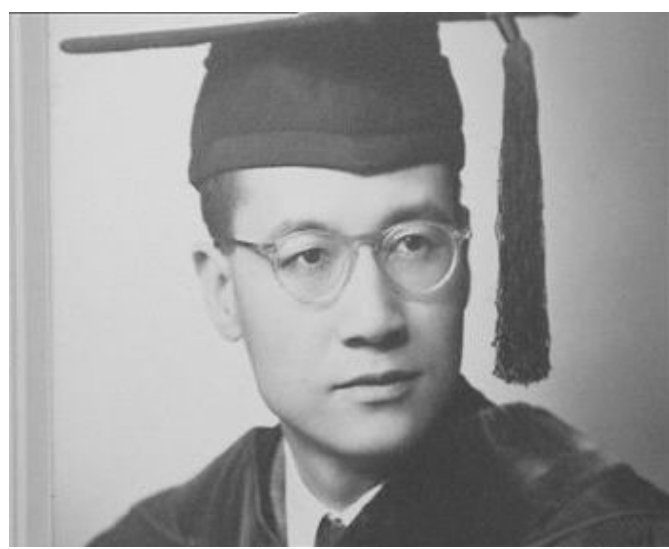

Figure 3. Tu-cheng Yeh (21 February 1916-16 October 2013). Source: courtesy of the Chinese Academy of Sciences.

Chengyi Fu (Fig. 2) was a well-known geophysicist who mainly engaged in solid geophysics, seismology, and geophysical exploration, and he became an academic at CAS. In 1944, he received his doctorate in geophysics from the California Institute of Technology (Caltech), and then he was employed as an assistant professor of geophysics there. In 1947, he returned to China as a senior researcher at the Institute of Meteorology at Academia Sinica and a professor of physics at Central University; in 1950, he served as a researcher at IGCAS.

Fu was a pioneer in the study of seismic wave theory. From 1946 to 1947, he published three papers entitled "Research on seismic wave" in Geophysics, an internationally authoritative American journal. He systematically studied the reflection and refraction of seismic waves, surface waves, and the propagation of head waves. In 1960, to commemorate the 25 th anniversary of the journal's publication, Fu was selected as a classic author of Geophysics by the journal for his original innovation.

Tu-cheng Yeh received his doctoral degree from the University of Chicago in November 1948 (Fig. 3). He was a meteorologist and an academic at CAS; he was once the director of the Institute of Geophysics, CAS. He initiated the meteorology of the Tibetan Plateau, the dispersion theory of atmospheric long-wave energy, and the theory of atmospheric circulation and seasonal abrupt change in East Asia. He also founded the theory of the adaptive scale of atmospheric motion, and he opened up a new field of global change science. His theoretical research played an important role in improving the level of meteorological operations in China, some of which are still playing a role. For example, the theory of atmospheric long-wave energy dispersion is commonly known as the upstream effect in operational weather forecasting; the theory of the formation and maintenance of blocking high pressure has always been an important theoretical basis for the forecast of continuous abnormal weather. His meteorological theory of the Tibetan Plateau has played an important 
role in China's meteorological industry in Wuzhong, as it is one of the important bases of weather forecasting and the main basis for climate forecasting. The scale theory of the adaptation of wind field and pressure field of atmospheric motion is still one of the main theoretical bases of weather analysis and forecasting.

The excellent work of these leaders in Chinese geophysics attracted attention in China, the United States, the former Soviet Union, and other countries. The professional knowledge, academic vision, and research methods acquired by these international students from abroad had a profound impact on Chinese geophysics. Due to the differences in academic levels at home and abroad at the time, these graduates who joined China's first-class universities or research institutes later were hired immediately as associate professors or full professors and served as leaders in this emerging discipline. After Jeou-jang Jaw assumed the role of director of the Institute of Meteorology, Zongqi Chen and Gongxu Gu of the National Academy of Peiping, Shanbang Li of the Central Geological Survey, Chengyi Fu, who studied in the United States, and Gangkun Zhu, who studied in the UK, joined in succession, and the strength of the discipline and research at the Institute of Meteorology was greatly enhanced.

Although CAS gathered the nation's top elites in science and technology at the time, there was a serious lack of reserve talent. Therefore, IGCAS strove to cultivate talent through a variety of channels.

Another important approach was through cooperation with institutions of higher education to develop geophysicsrelated majors and teaching and research offices in a coordinated way. This included the establishment of a geophysics department or teaching and research offices at a comprehensive university (Table 2) and setting up specialized majors at professional colleges. CAS planned to use its expertise in science and technology to cultivate talent, and so they established the University of Science and Technology of China in 1958, which adopted a policy of running the university through the whole academy, combining institutes with departments. IGCAS was mainly responsible for the development of the Department of Geophysics, which created three majors (i.e., radio, space physics, and atmospheric physics) and four teaching and research offices (i.e., high-altitude atmospheric physics, meteorology, seismology, and telemetry and remote control). IGCAS provided the backbone of scientific research to teach classes at the university and to help build laboratories. The University of Science and Technology of China (Fig. 4) established a graduate school in 1964, and the Department of Geoscience enrolled new students, but it was suspended later due to the Cultural Revolution (Fang and Zhang, 2012).

\subsection{Capacity building for science and technology}

Scientific progress is not only the successful implementation of policy but also the development of scientific capac- ity, expertise, and discoveries. Most scientific achievements are related to advanced technical means, which include the construction of observation stations, the development of advanced detection instruments, and a rich collection of data, all of which have promoted the development of older disciplines.

In the mid-1950s, geophysics in China was still at the stage of backward empirical science. Being aware of the imperative for large-scale, modern scientific research, Jeoujang Jaw promoted the policy of physics, engineering, and new technology transformations as the overall direction for the discipline of geophysics. In the physics transformation, the vigorous development of dynamics research transformed geophysics from a descriptive science to one that was based in mathematics and logic. The transformation of engineering reflected both the characteristics of the modern scientific research of big science and the need to transform scientific research results into productivity to push national economic development. This entailed the use of new technology armed geophysical observation (Yeh et al., 2007). This three transformations policy produced a profound influence on the development of IGCAS.

During the International Geophysical Year (IGY) in the 1950s, IGCAS established seven geomagnetic stations. The national seismograph network had been established to carry out geomagnetic measurements in the field (Zhou, 2007). The stations that already existed, which included Beijing, Sheshan, Guangzhou, Changchun, and Lhasa, took part in the IGY (Zhu, 2007a). To make these five avenues world class, Zongqi Chen sent people to the former Soviet Union's Institute of Geomagnetic, Ionospheric, and Radio Wave Propagation to compare the Sheshan geomagnetic station with Moscow, and he produced four sets of Schmidt standard geomagnetic theodolites from Germany, and he also sent people to study there. The coefficient of the Chinese geomagnetic station instrument was accurately determined, which met the standards of the international level. After that, Chinese scientists repeatedly took measurements at several geomagnetic stations in China, and at international standard geomagnetic stations abroad, to help meet international standards in measurements at the Chinese facilities. This resulted in accurate data that were provided by China during the IGY, which was why China was recognized and respected by the international community. To meet the urgent needs of the national economy and national defense construction, Chen personally organized researchers to compile the results of field geomagnetic surveys over the years into China's geomagnetic map (1950.0).

Until 1958, IGCAS used seismographs made with the assistance of experts from the former Soviet Union to complete the construction of 20 basic seismic stations in China. In the 1960s, high-sensitivity, short-period seismographs were developed, which greatly improved the accuracy in the measurement of basic seismic parameters (Zhuang and Yan, 2007). In the late 1950s, the institute successfully organized 
Table 2. Majors and research offices established in higher education institutions with the help of the IGCAS.

\begin{tabular}{llll}
\hline No. & Year & Major & Cooperative university \\
\hline 1 & 1953 & Teaching and research office and major in physical prospecting & Beijing Geological College \\
2 & 1956 & Geophysics & Peking University \\
3 & 1958 & Department of Geophysics & University of Science and Technology of China \\
4 & 1962 & Crustal physics & University of Science and Technology of China \\
5 & 1977 & Department of Earth and Space Science & University of Science and Technology of China \\
\hline
\end{tabular}

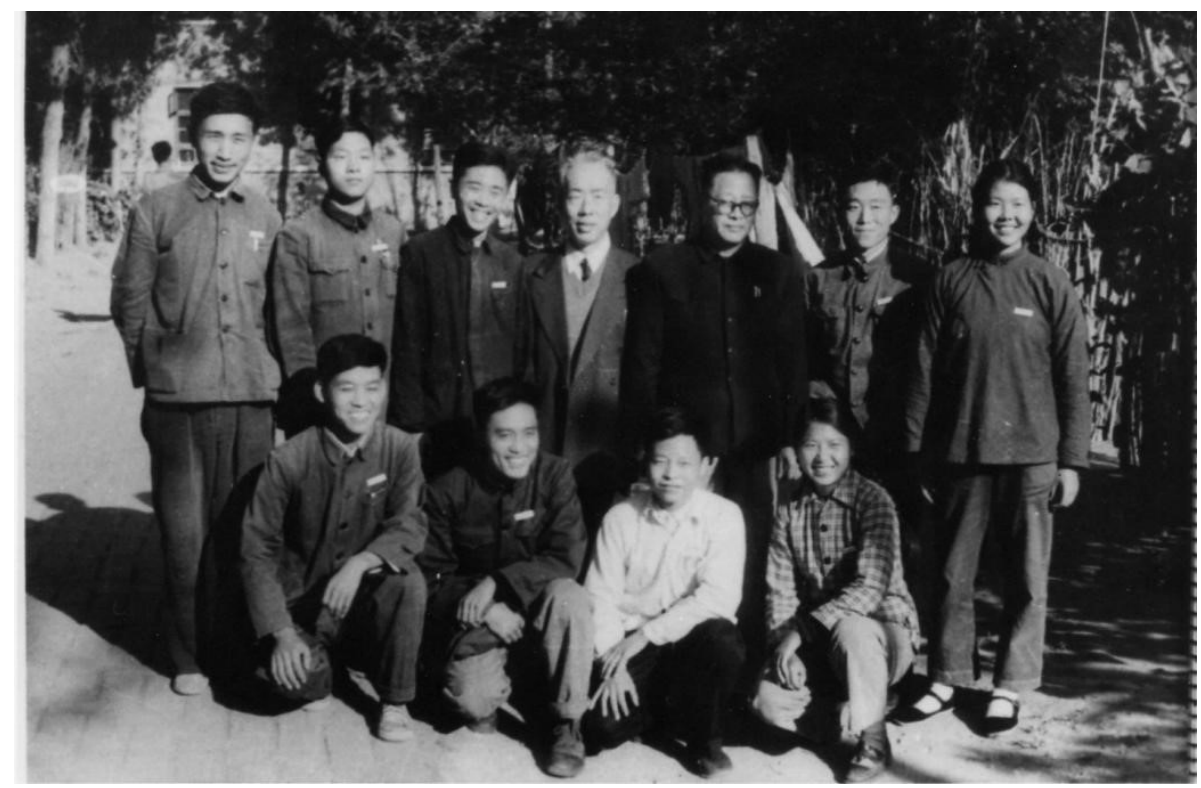

Figure 4. In 1964, Jeou-jang Jaw and Ganchang Wang took a group photo with the first geophysics graduates at the University of Science and Technology of China. Source: courtesy of the China University of Science and Technology archives.

and established regional seismic station networks. In 1959, earthquakes continuously occurred after the Xinfengjiang Reservoir in Guangdong was impounded, which garnered a high degree of attention from the Central Committee of the Communist Party of China (CCCPC). IGCAS constructed a network of seismic observation stations on the site (Fu, 1990) and proposed tentative ideas about the causal mechanism of earthquakes. In 1962, the institute organized and established the Engineering Seismology Laboratory.

In the earlier period, after the founding of PRC, geomagnetic research focused on the utilization of geomagnetic data and the construction of technological infrastructure for geomagnetism. IGCAS actively opened up the development path of geomagnetic science with a focus on establishing new geomagnetic stations, strengthening the management of observational data, and importing a large amount of geomagnetic and ionospheric observational data from foreign data centers.

During the early days of the Cultural Revolution, IGCAS also had eight observatories, 15 seismic stations, and sea wave observation stations in addition to multiple laboratories. IGCAS even had the 581 instrument factory to coor- dinate the development of artificial satellites (The Editing Committee of the Geophysical Society, 1989).

From 1957 to 1958 , the IGY launched multidisciplinary geophysical observations globally, and China was an important participating state. The Chinese government established the China Committee on 18 June 1956. Except for solar observations and some satellite observation projects, the observation projects carried out by China were set up at observatories of IGCAS. Through Jeou-jang Jaw's application to CAS, the Academy of Sciences of the former Soviet Union sent a group of experts to deliver relevant instruments and scientific research data to China, and the two countries acquired a large number of observational equipment in fields such as seismology, geomagnetism, and space exploration. Later, accompanied by experts from IGCAS, Russian experts went to many places in China to conduct investigations and proposed development plans for different academic majors in geophysics in China.

Later, due to the issue of the so-called two Chinas, the Chinese government started to withdraw from this IGY program, but the various originally scheduled observational activities proceeded as usual, which accumulated abundant data. These 
relevant stations and the continuous publication of geomagnetic observational reports won one gold award and seven silver awards, at the centenary of the International Geophysics Observation, which were awarded by the International Association of Geomagnetism and Aeronomy (IAGA; C. R. Liu, 2007), proving later that these activities played an important role in the development of geophysics in China (Zhu, 2007b).

In 1964, IGCAS was in urgent need of developing new detection experimental technology and advocated means to apply various types of radio waves, acoustic waves, and laser technology to atmospheric detection. In 1966, Yanzeng Zhao (Jeou-jang Jaw's elder daughter) and eight other people developed the first pulse ruby laser radar in China and carried out detection and research on atmospheric elements such as clouds and smoke, atmospheric extinction coefficients, and atmospheric visibility. This work was at an advanced level in China and was comparable to the international standards at that time.

\subsection{Policy support and organizational structure}

As one of the first 13 research institutes at CAS, IGCAS initially set up four research groups, namely meteorology, seismology, geomagnetism, and physical prospecting $(\mathrm{Qu}$, 2007, p. 503). Afterward, it also successively established the engineering and earthquake research group, the physical prospecting laboratory, and the sea wave research group. Later, due to development within the institute, the four research groups were changed into five laboratories, and the high-altitude exploration laboratory was added.

As a socialist country, scientific development in China was affected to a great extent by national scientific planning. In March 1956, the State Council formulated the 12 year (19561967), national long-term plan for the development of science and technology and put forward the policy of "missions drive disciplines". Jeou-jang Jaw served as the chief of the Earth science special topic and ocean group. At a meeting, it was decided that research on China's seismic activity and disaster prevention would be listed as the 33rd item in the National Important Scientific and Technological Mission (Jaw, 1957a); marine science was listed as the seventh item (Chinese Society of Oceanology and Limnology, 1989).

From 1958 to 1965, IGCAS developed rapidly. The institute underwent drastic changes in institutional adjustment. Mission formulation and execution were affected by social, political, and economic factors; the sustainability of the development of the discipline was disturbed by frequent institutional adjustments. During the Great Leap Forward, Threeline Construction, and the Cultural Revolution, IGCAS was divided and integrated multiple times. In the 1950s, CAS integrated the dispersed power of multiple research departments to establish a unified research institute, which was in line with the needs of the development of the discipline. From the 1950s to the mid-1960s, with the needs of national economic development, multiple research institutes were separated, and the scientific research direction for some of the research groups changed suddenly. For example, due to the development of artificial satellites, the physical prospecting group suddenly turned to the telemetry and remote control of artificial satellites, which was not conducive to the sustainable development of the discipline. During the Cultural Revolution, except for the continued development of seismological research, other branches collapsed. By the end of the 20th century, these research institutions were reintegrated. The separation and integration among institutions was a reflection that the institute has always been erratic about the relationship between theory and practice, politics and business, and so on (Fortieth Anniversary Editing Committee of the Institute of Geophysics, 1990).

During the Cultural Revolution, science and technology in China entered a decade of darkness, which brought a substantial blow to the development of geophysics in China. However, seismological and geomagnetic work were able to continue due to real needs and state support.

\subsection{International exchanges with the former Soviet Union and European countries}

International exchange is not only important but necessary for the development of disciplines. IGCAS maintained close contact with the former Soviet Union in the early 1950s.

From the 1950s to the 1970s, international cooperation at the CAS focused on the former Soviet Union. From 24 February to 26 May 1953, CAS organized a delegation to visit the former Soviet Union for about 3 months. This included the director of IGCAS, Jeou-jang Jaw (Fig. 5). The delegation visited the Institute of Geophysics, the Academy of Sciences of the former Soviet Union, and other institutes related to meteorological and geophysics (Jaw, 1953a, b).

The Chinese delegation also participated in the Western Pacific Regional Conference of the IGY that convened in Tokyo in February 1957; Changwang Tu, Hang Li, and Jeoujang Jaw were elected as executive committee members of the conference (Jaw, 1957b). Based on the above exchanges, Tu and Jaw visited Japan from July to August 1957. Jaw focused on the effects of the Tibetan Plateau on westerly winds (Chinese Meteorological Society, 2002).

After the founding of the People's Republic of China, in the face of the blockade by the United States and other Western countries, in February 1953, Mao Zedong called on a nationwide study of the former Soviet Union. In early 1953, CAS decided to send a huge delegation to the former Soviet Union to learn how the Russians organized and led scientific research (Wu, 1991).

From 1955 to 1956, following Sino-Soviet exchange activities in seismological science and technology, IGCAS sent students in related majors to the former Soviet Union for further studies in geophysics, seismic geology, the development of seismic instruments, observational data analysis, earthquake engineering, and so on (Table 3). These people re- 


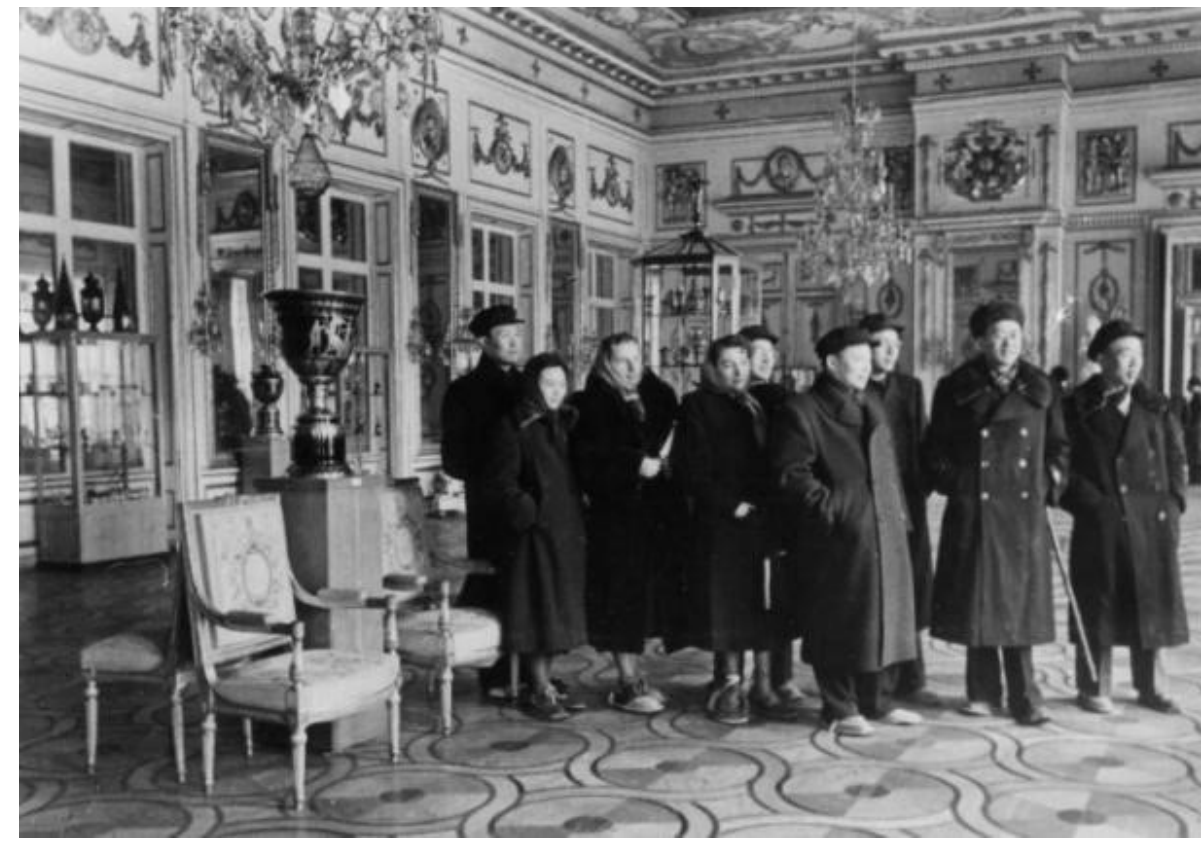

Figure 5. Jeou-jang Jaw (first row, starting from the right) with Luogeng Hua and Sanqiang Qian as the members of Chinese delegation visited the former Soviet Union in 1953. (Source: commemorative volume on Jeou-jang Jaw's 100th birthday; edited by the National Space Center, CAS, 2007.)

turned later, after their successful studies, and became the backbone of China's seismological undertakings (Xie, 2007).

From 1955 to 1960 onwards, IGCAS invited many Russian experts to guide the work in China, purchased and learned advanced Russian equipment, and sent Chinese personnel to the Soviet Academy of Sciences to obtain an associate doctorate or to do further study. These exchanges covered the basic fields of geophysical research missions. Since 1956, IGCAS successfully dispatched visiting scholars, associate doctoral students, graduate students, and university students to the former Soviet Union to study earthquakes. Jeou-jang Jaw also contacted the Institute of Building and Building Materials of the Academy of Sciences of the former Soviet Union in 1958 to ask for assistance in mentoring graduate students (Institute of Geophysics, 1958). IGCAS's international cooperation was influenced by geopolitics in that IGCAS and Japan cooperated, using IGY activity as a bridge, and Japanese experts also visited China to investigate meteorological observations using sounding rockets.

However, in early 1960, IGCAS members Jaw, Yeh, and $\mathrm{Gu}$ participated in the International Conference on Numerical Weather Forecasting hosted by the Japan Meteorological Society (IGCAS, 1960). Later, Jaw refused to continue to cooperate with Japanese colleagues because of the opposition to China in Japan (Liaison Office of the CAS, 1960). Coincidentally, in early 1962, the Committee on Space Research (COSPAR) invited China to a meeting in Paris to discuss the eight different activities in the fields of geomagnetic, meteorology, and aurora from April 1964 to the end of December
1965. Later, the Chinese responded that if Taiwan participated then China would not participate to avoid the issue of the two Chinas (Fan, 2009).

Although there was no academic exchange with the United States, IGCAS had relatively close exchanges and personnel visits with European countries, especially Sweden and France. Chinese geophysicists visited the other party's meteorological stations, large-scale environmental simulation equipment, geomagnetic stations, ionosphere stations, and sounding rocket launch sites many times. They have maintained exchanges in the fields of the ionosphere, space exploration, and radio wave propagation and carried out space science and artificial rainfall and the development of artificial satellites has provided valuable inspiration. In June 1963, Jaw and Ji Qian were invited as observers to Warsaw, Poland, to participate in COSPAR. Through these domestic and foreign academic activities, Chinese geophysical scientists and technicians established a good communication platform with their international counterparts, but substantial international scientific cooperation came even later.

\section{Active scientific achievements of various sub-disciplines of geophysics in PRC}

At the beginning of PRC's establishment, in context of being isolated by the United States and European countries, domestic poverty, and military weakness, it was China's first mission to build a national economy and national defense. During this period, in addition to achieving breakthroughs 
Table 3. List of people sent by IGCAS to the former Soviet Union for advanced studies between 1955 and 1956. (Source: Chinese Geophysical Society, 2012.)

\begin{tabular}{lll}
\hline Type & $\begin{array}{l}\text { Number } \\
\text { of people }\end{array}$ & Major \\
\hline Visiting scholars & 3 & Seismic observation and analysis (1); geophysics and seismic survey (2) \\
Advanced students & 4 & Seismic instruments (2); seismic geology (1); geophysics (1) \\
Graduate students & 3 & Seismic observation and analysis (2); earthquake engineering research (1) \\
University students & 2 & Geophysics \\
\hline
\end{tabular}

in the four traditional fields of meteorology, seismology, geomagnetism, and physical prospecting, IGCAS also developed emerging fields, such as weather forecasting and space physics.

\subsection{Great breakthroughs were made in meteorology by rooting in special topography of China}

Since the establishment of PRC in 1949, the distribution of the meteorological network became more intensive, and the business of weather forecasting expanded continuously. This prompted IGCAS researchers to conduct extensive research on atmospheric circulation in East Asia and the weather and climate in China. Through these studies, people developed a better understanding of the characteristics of atmospheric circulation in East Asia, of systematic activity that affected China's weather, and methods for forecasting this activity.

Yibing Xie, Tu-cheng Yeh, and Xiaolan Guo completed their doctoral theses under the guidance of CarlGustaf Arvid Rossby (1898-1957) when they studied at the University of Chicago, USA, in the 1940s. Xie and Yeh later went back to China. Xie went to Peking University, Yeh joined IGCAS, and Guo stayed in the United States. The Chicago-based school founded by Rossby had a very distinct academic style. It emphasized the study of atmospheric science from the most basic principles of physics or fluid mechanics rather than studying atmospheric phenomena directly. This academic spirit was also an important reason why Xie and Yeh made many pioneering contributions in the field of meteorology when they were at the University of Chicago and after they returned to China.

Yeh made a world-class theoretical breakthrough when he studied under Rossby. Yeh published a famous paper titled "On energy dispersion in the atmosphere" in the Journal of Meteorology, which was an American journal. Yeh put forward the theory of the energy dispersion of the atmospheric plane, known as the Rossby wave, which theoretically proved that the energy in the circulation of west winds traveled downstream (or upstream) at a group speed that is much faster than the wind speed. This provided a theoretical basis for the prediction of the long wave of modern atmosphere and also provided a dynamic explanation for the generation, maintenance, and movement of a blocking highpressure weather system. Yeh asserted in his article that "af- ter a strong disturbance occurs somewhere in the westerly belt, it would also occur in a certain distance downstream (East Side)" (Yeh, 1949). Yeh was one of the greatest meteorologists in China in the second half of the 20th century.

At the same time, dynamic meteorology and the theory of atmospheric circulation were developing fast. People tried to understand how the current state of atmospheric circulation was formed and maintained. According to worldrenowned meteorologist Victor Starr, who was Rossby's student, to maintain the angular momentum balance in the atmosphere, atmospheric disturbances (grooves, ridges, high pressure, low pressure, etc.) played a major role, and longwave trough lines and ridges were tilted from northeast to southwest (White, 1949).

Yeh's research showed that not only the angular momentum but also the vorticity should be balanced in the atmospheric circulation. The long-wave trough line and ridge line should not only be inclined but also spiralled, which was more consistent with actual observations.

At that time, there were the following two views on how to maintain the state of atmospheric circulation: one side believed that, in the mechanism to maintain balance in the global angular momentum, Hadley circulation at a low latitude was also very important in addition to atmospheric disturbance. Another point of view was that Hadley circulation was not important, and this side doubted whether Hadley circulation even existed. In 1950, Herbert Riehl and Yeh published a famous paper titled "The intensity of the net meridional circulation" in the Quarterly Journal of the Royal Society in England (Riehl and Yeh, 1950). In that paper, a large quantity of wind data on oceans were analyzed, and the existence of Hadley circulation was confirmed for the first time. These papers by Yeh soon attracted the attention of the international meteorological circle and were regarded as classic works in dynamic meteorology and atmospheric circulation theory. Yeh himself was recognized as a member of the Chicago school represented by Rossby, which had a great influence on the development of modern meteorology (Yeh, 2008). This theory was popularized by Brian John Hoskins's great circle theory 31 years later as a theoretical explanation for remote correlation and remote response.

In the mid-1950s, Yeh and meteorologists Zhenchao Gu, Shiyan Tao, and Jianchu Yang published three papers in 
the journal Tellus, which revealed the dynamic and thermal structure and interannual variation in the mean atmospheric circulation over East Asia in winter and summer, which attracted international attention (Yeh, 1958). These meteorologists learned about the characteristics of East Asian atmospheric circulation, mastered an understanding of the system activity that affected weather in China, and explored ways of forecasting this activity (CAS, unknown year). This study was very useful for forecasting weather in China. In the early 1950s, Yeh, Tao, and Li Maicun found that the circulation in East Asia and North America exhibited a sharp change during the transitional seasons (spring and autumn). In these two areas, the annual variation in atmospheric circulation was periodic rather than gradual, with a smooth transition, which was of great significance for weather forecasting. Because of its unique academic contribution, this research result has attracted wide attention at home and abroad. In the 1950s, numerical experiments of atmospheric circulation also showed this sudden change.

Yeh also proposed a dynamic explanation for the formation, maintenance, and movement of high pressure, which is an important weather system. He was one of the first scholars in the world to study the mechanism of blocking high pressure. The book titled The study of obstructing high pressure in the Northern Hemisphere, which was coauthored by Shiyan Tao, was acclaimed widely by the meteorological community (Yeh and Zhu, 1963). In 1958, Yeh and Baozhen Zhu coauthored the book titled Some basic problems of atmospheric circulation, which comprehensively summarized the main facts of atmospheric circulation and discussed the essence of these facts and their mutual relations. This book was one of the first important works to thoroughly understand the evolution and maintenance of atmospheric circulation. It was highly praised in meteorological circles at home and abroad and translated into Russian (Yeh, 2008).

In the 1950s, Yeh studied the adaptation theory of atmospheric motion. Before 1940, it was believed that, in the large-scale motion, the pressure field first changed, and then the wind field changed, so as to adapt to the change in the pressure field to become quasi-geostrophic motion. In the 1940s, Rossby explained theoretically that the change in large-scale motion was not dominated by the pressure field but by the wind field. The wind field changed first, and the pressure field changed according to the wind field. Was it the pressure field or the wind field? After in-depth study, Yeh put forward his own viewpoint in 1957. The large-scale motion was still dominated by the change in the pressure field, but the small-scale motion was dominated by the change in the wind field, which showed that the concept of largescale quasi-geostrophic motion was affected by scale. In the early 1960s, Yeh and Li Maicun proposed that there was a quasi-equilibrium relationship between the wind field and the pressure field with respect to middle- and small-scale motion. This relationship was nonlinear rather than linear quasi-geostrophic (Yeh and Li, 1964). Later, many nonlinear studies appeared abroad. From the late 1970s to the early 1980 s, Yeh and Li put forward that there were three different timescales in the generation and development of atmospheric spatial-scale systems. This was the famous theory of atmospheric motion adaptation, which greatly enriched the theory of atmospheric circulation (Yeh, 2008).

As early as the early 1950s, when international attention was focused on the dynamic forcing of the plateau, Yeh proposed that the Tibetan Plateau was a heat source in summer and a cold source in winter, and asked what the impact of this phenomenon is on the general circulation in East Asia. His concept that the heat sources of this plateau were important was gradually accepted internationally (Sun, 2012). Yeh and his colleague Youxi Gao jointly completed the writing of "Meteorology of the Qinghai-Tibet Plateau", which later had a huge impact on the research of world meteorology.

In addition, during the 1950s and 1980s, Yeh led a group of young Chinese scientific researchers doing unique research on the meteorology of the Tibetan Plateau. Before the 1950s, the study of meteorology of the Tibetan Plateau generally focused on the dynamic forcing of the plateau. In the early 1960s, Yeh and climatologist Hermann Flohn, respectively, pointed out that the Tibetan Plateau was a huge heat source in summer. Yeh also pointed out that the Tibetan Plateau was a cold source in winter in China, and he also studied the heat source over the Tibetan Plateau in summer and its influence on atmospheric circulation in East Asia. Since then, the concept of the influence of the Tibetan Plateau (and other large terrain) on atmospheric heat sources has been accepted internationally. Yeh first discovered that, when the westerly belt crossed the Tibetan Plateau from west to east, the westerly belt could be divided into two branches; one was called the northern branch westerly jet, which bypassed the northwest side of the Tibetan Plateau and passed through the lower reaches of the Yangtze river to Japan. Yeh pointed out that when the southern branch westerly jet crossed the southern margin of the Tibetan Plateau from south to north, the central height of the jet decreased significantly due to the heating effect of the Himalayas, which affected the flight path of the southern branch. This discovery attracted the attention of scholars at home and abroad, which led to a series of studies on these two westerly jets (Yeh, 2008).

Zhenchao $\mathrm{Gu}$ also studied the dynamic influence of the Tibetan Plateau on East Asian circulation and its importance $(\mathrm{Gu}, 1951)$. Yeh and $\mathrm{Gu}$ also analyzed the specific dynamic effects of the Tibetan Plateau on the atmospheric circulation in East Asia and the weather in China, which included branching and convergence, inhibition and generation, the barrier effect, and how the thermal effect of the Tibetan Plateau caused great changes in atmospheric temperature over the plateau in summer and winter. The Tibetan Plateau is the highest plateau on the surface of the Earth. It has a profound impact on China's weather and climate 
and the atmospheric circulation of the entire Northern Hemisphere.

\subsection{Progress in space physics}

In 1957, Russia launched the first artificial satellite. Many Chinese scientists were well aware that satellites were an important technological platform and were important support for space physics research. They realized immediately the influence of space physics on space activity and carried out extensive, multi-level and multi-means research work in space physics. Jeou-jang Jaw believed that "the dream for many years for the establishment of a laboratory in cosmic space to study the correlation of phenomena between geophysics and astrophysics had finally come true" (Jaw, 1957c).

To have the opportunity to engage in professional research in the not-too-distant future, the government had to fully support China's launch of a satellite as soon as possible, even though they had limited economic and technological resources. It was the common destiny of many scientists who had studied overseas to be transformed into engineers. Between the 1950 s and 1970 s, many of them took part in the national defense project of the PRC titled "two bombs and one star", which referred to nuclear bombs, missiles, and artificial satellites. The lucky and smart ones were also able to seize the opportunity and use "missions drive disciplines" to do some basic research.

After the CCCPC approved the development of an satellite by CAS, between July and August of 1958 the CAS established the 581 group (September 1958-November 1959), which specialized in preliminary research on artificial satellites and was set up within IGCAS. An aerodynamicist who was a professor at the California Institute of Technology and Theodore von Kármán's proud student, Xuesen Qian, served as the group chief, and geophysicist Jeou-jang Jaw, red cadres of the Communist Party, and the secretary of the Party Committee of IGCAS, Yiqing Wei, served as deputy group chiefs.

To learn from Russia how to make satellites, Jaw led a delegation of atmospheric physicists from CAS to the former Soviet Union in October 1958 to study satellite research and development and space research. The delegation visited and observed astronomical observatories, the space electronic lock, the Institute of Applied Geophysics, and other institutes in Russia. They saw some high-altitude detection instruments; however, due to confidentiality, the Russians did not allow the delegation to visit and observe more important projects (Tsinghua School History Committee, 2001). During the Great Chinese Famine from 1958 to 1960, the CCCPC instructed that the development of an artificial satellite should continue but at a slower pace. Jaw proposed a revised five-step strategy for space exploration by China, that is, to "use rocket exploration to train researchers and take highaltitude physical exploration as a foundation to develop satellites, explore the direction of satellite development, construct the Space Environment Simulation Laboratory, and carry out research on the ground-tracking equipment." (Chen, 2003).

When research on magnetospheric physics and the solar wind had just started internationally, Jaw paid special attention to the plasma physics research of the famous Swedish physicist and electrical engineer, Hannes Alfvén, who later won the Nobel Prize for Physics in 1970. Jaw established the magnetic storm group at IGCAS in 1959, and he established a plasma simulation laboratory by drawing on Alfvén's experience in the ground laboratory, where they had conducted plasma simulation experiments (Z. X. Liu, 2007). He introduced mathematical physics into geomagnetic research, combined space physics and international experience, and proposed a research method that combined "theoretical research, field observation, space exploration, and experimental simulation" (Chao, 2007). The magnetic storm group used an abandoned bicycle shed that they transformed into an isospace plasma simulation laboratory, and they carried out a plasma simulation experiment on the change in the Earth's radiation zone during the magnetic disturbance by referring to the method of gas discharge by Alfvén (Xu, 1992).

From the second half of 1960 to 1964 , Jaw spent 2-3 years establishing a magnetic storm research team, completing the laboratory construction, and leading the team to gratifying research results; they published more than 20 papers. In June 1960, Jaw and Ronglan Xu published "Changes in storm's capture area during geomagnetic disturbance" in the journal Geophysics (Xu and Jaw, 1962). The article proposed that changes in the Earth's magnetic field, caused by magnetic disturbances, opened the capture area around the Earth, which allowed a large number of charged particles to enter the vicinity of the Earth and be captured by the geomagnetic field. Then, based on this result, a simulation experiment of the change in the particle motion area during the magnetic disturbance period was carried out, and the result was very consistent with the theory. When Jaw participated in the International Space Research Conference in 1962, these results were well received by international colleagues (Jaw et al., 1963). In 1963, Zhao and his colleagues published a paper on the moving region of charged particles in the dipole magnetic field and its model experiment. The curve obtained by the study of the relationship between the intensity and energy of the example in the radiant zone, which was jointly developed by Zhenxing Liu and Zuyin $\mathrm{Pu}$, was similar to the results obtained by the second and third satellites of Russia (Jaw, 1968).

In the 1960s, Zhenxing Liu proposed a new rational theory and a method of regional division of gas dynamics by using data from rocket and satellite exploration of the upper atmosphere. The main results were published in the Chinese Journal of Geophysics. Yaowu Chen developed the subatmospheric long-wave model. He used the layer-by-layer approximation method to calculate the upper atmospheric temperature profile from satellite orbit damping data. He proved that the temperature distribution of the thermosphere 
was unsaturated, and its gradient changed with local time, geographical latitude, and solar activity index 2 (Chen and Yaowu, 1963). Later, he conducted research on the heating source of energy in the upper atmosphere, the diffusion process, and the vertical dynamic transfer of components. He proposed the concept that the height at which diffusion separation was not fixed and that there was a transition layer. $\mathrm{He}$ also developed the vertical dynamic transfer function to describe the transition layer (Chen and Yaowu, 1980).

In June 1963, Jaw participated in the COSPAR conference. He presented an academic report on the movement of charged particles in the dipole magnetic field capture area during the magnetic disturbance and its simulation experiment results. At the time, Fred S. Singer, director of the National Weather Satellite Service, thought that this work was very meaningful. It was published in the Science Bulletin in November 1963 and was titled "Progress in solar wind, magnetic field in outer space, and detection of low energy charged particles" (Jaw, 1963). In 1964, he published the English version in Science of China, and it was titled "Motioned regions and model experiments of charged particles in dipole magnetic fields" (Jaw, 1963, pp. 56-57).

At the suggestion of Jaw and IGCAS, Swedish physicist Hannes Alfvén was invited by CAS to China, and he presented a series of lectures during his month-long visit in September 1963. He visited Beijing, Shanghai, Hangzhou, and Nanjing and gave several lectures on "The importance of Magnetohydrodynamics (MHD) in physics and Astronomy", "Recent development of space plasma physics", and "MHD and the origin of the solar system" (Xu, 1992; Zhang and Yin, 2019). Alfvén actively promoted exchanges between the scientific community of China and Sweden, and he actively helped collect data on plasma gun experiments (Zhang and Yin, 2019). At the request of the Chinese, he also sent plasma guns and Kerr cell shutters for high-speed cameras. In 1965, when Jaw visited Sweden at the invitation of Alfvén, he made a summary report for the Institute of Plasma Physics of the KTH Royal Institute of Technology of Sweden on using theoretical research and model experiments to investigate the structure and change of the radiation band during a magnetic storm. Later, the English version was published in Science China, which was a summary of the pioneering research achievements of the magnetic storm group in space physics in recent years (Jaw, 1968). In 1965, the Sputnik project had resumed, but basic research in space physics had been suspended because of the notion embodied in the slogan "theory divorced from practice".

At the beginning of the Cultural Revolution in 1966, the theory group of geomagnetic storms and the plasma simulation laboratory were regarded as a black mark on the record of Jaw; his work was halted permanently. After 1967, research on magnetospheric physics was mainly to provide space environmental data for satellite development missions and to conduct ground simulation tests of satellite space particle radiation. This continued until 1970 when all the equip- ment for the study of magnetic storms was dismantled and the laboratory completely disappeared.

\subsection{Applying basic research closely related to national economy}

\subsubsection{Numerical weather prediction}

Numerical forecasting and the work of medium- to longterm weather forecasting and agrometeorological research were also performed (Jaw, 1959). In 1961, Qingcun Zeng first created semi-implicit differential method of numerical forecasting. This achievement was immediately applied at the World Meteorological Center in Moscow, and the accuracy of the forecast increased to the unprecedented level of $>60 \%$, which brought numerical forecasting to the forefront of weather prediction. Later, he developed methods such as the standard layer knot deduction and square conservation scheme, which are still the core technologies for the world's numerical weather and climate prediction. Since then, Zeng has solved the basic theoretical problems of atmospheric remote sensing and has written the first monograph on a quantitative theory of satellite remote sensing in the world. The concept and method of best information layer proposed by Zeng are an extremely important means for monitoring corresponding disasters such as rainstorms and typhoons. His inversion algorithm for solving the remote sensing equation became the main algorithm of the main satellite data processing and service centers in the world (Editorial office, 2020).

\subsubsection{Seismology}

In the 1950s, observation and theoretical research in modern seismology in China was basically introduced to China from the former Soviet Union, Europe, the United States, and Japan. From the 1950s to 1960s, China concentrated on imitating and building seismological instruments and observation systems and sorting historical data about earthquakes in China, all of which reached the international standard for accuracy and thoroughness. At the same time, basic research in seismology in China developed simultaneously with that of the West, and research on earthquake theory also progressed. When IGCAS began the theoretical study of seismic wave propagation in the early 1950s, Chengyi Fu achieved beneficial results in the physical interpretation of the method of the stratified medium theoretical calculation of the Rayleigh equation and the application of seismic waves in exploration. Fu had some achievements in some problems about elastic wave propagation theory and seismic exploration, which included the energy beam of a seismic surface wave, concentrated influence of surface soil on seismic exploration, and irrelevant root of Rayleigh wave equation, all of which were used for reference purposes by the former Soviet Union.

The seismic wave waveform fitting method has been used widely to study the seismic source process and the structure 


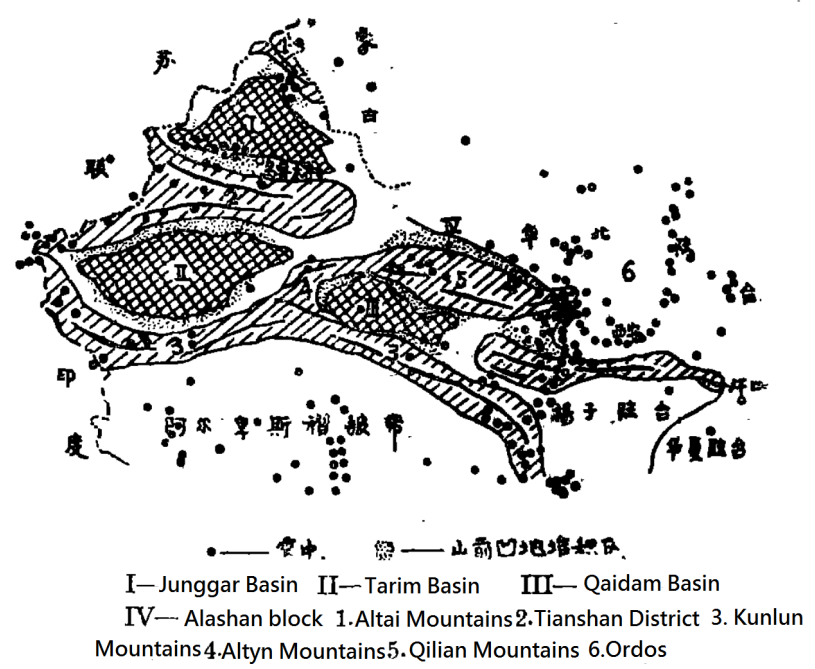

Figure 6. Map of earthquake intensity in China. (Source: Li, 1953.)

of the crust and upper mantle and was also applied to the propagation of seismic waves in complex structural media. Using ground observational data to infer the Earth's internal structure and source parameters was called a geophysical inversion problem. The inversion of the $3 \mathrm{D}$ velocity structure made it possible to study the topography of the Earth's internal structure. On this basis, the 3D velocity structure of the crust and upper mantle in this area was reconstructed based on the $\mathrm{P}$ wave arrival data from mainland China. On these theoretical issues, Fu made relatively outstanding contributions. The method of predicting earthquakes to within 3 years proposed by $\mathrm{Fu}$ in 1963 is still used to this day (Fu, 1963).

In view of the 33rd earthquake tasks, Chengyi Fu took the lead in proposing scientific approaches and measures for solving issues that were related to earthquake prediction, which was 8 years earlier than the formulation of an earthquake prediction plan in Japan and the United States (Y. T. Chen, 2007, p. 122). At the time, his colleagues in the international seismic community highly praised his early research work. After that, Fu's main focus was devoted to education, and there was no more theoretical output.

Historical seismology is a unique research field in China, which was funded and developed by Chinese people due to the demand for disaster reduction. Research on source physics also made progress. Plate tectonic theory has so far successfully explained the causes of earthquakes in the ocean and along continental margins. There are still many unresolved problems for inland earthquakes, especially those in mainland China. At present, China's research on source physics is largely focused on the motion learning process (Fu and Chen, 1979). Also, Yuntai Chen, Zhenxing Yao, and Futian Liu applied the method of fracture mechanics to study the physical mechanism of the local instability process of tectonic deformation and used the propagation model of plane shear cracks in rheological media to illustrate the exis- tence before the earthquake. There are various forms of this creeping phenomenon prior to an earthquake. Through nearfield recording study, they had a specific understanding of the complex rupture process at the source, and they established a corresponding source model that explained that uneven rupture on the fault plane was an important factor for high-frequency radiation. For the study of theoretical seismograms, the work of using generalized reflection and transmission coefficient matrices and discrete wave number methods to calculate near-field theoretical seismograms was completed. At the same time, further decomposition of the transfer matrix was achieved, which sped up the calculation of theoretical seismic maps.

In addition to the theoretical study of seismic waves, the construction of seismic stations and historical seismic data collation was also an important basis for carrying out seismological research. In the early 1950s, large-scale capital construction required information on the seismic intensity at the site. In 1953, CAS established the Earthquake Working Committee chaired by Siguang Li and Kezhen Zhu. The main mission was to collect, check, and sort the historical data on earthquakes at the construction site and to put forward comprehensive opinions about their probable intensity. Under the auspices of Wenlan Fan, the Third Institute of History of CAS worked closely with IGCAS to publish a twovolume China Earthquake Data Chronology in 1956. It became the longest record on earthquake history in the world, which laid the foundation for the study of earthquake activity in China (Fu, 1990, pp. 5-6), and it was widely used as reference material to evaluate the seismic intensity of various regions.

The map of earthquake intensity in China was produced (Fig. 6). The internationally used seismic intensity scale was the $12^{\circ}$ intensity scale of the modified Mercalli intensity scale, but seismologists of various countries also increased or decreased the scale according to their specific conditions. In 1955, with the assistance of Russian expert Sergei Medvede, the seismological Working Committee of the Chinese Academy of Sciences conducted a comprehensive study based on census data. Yushou Xie compiled an earthquake intensity map for China. This intensity map, based on China's national conditions, was popularized in 1959 (Xie and Yushou, 1957). Chengyi Fu and Shanbang Li studied the relationship between epicenter intensity, I0, and surface wave magnitude, $\mathrm{M}$, in China, and the relationship between $\mathrm{M}$ and seismic wave energy, E, and obtained an empirical formula. Chengyi Fu and Zhengrong Liu also developed a macro method to determine the depth of the source by the intensity distribution. Although the formula only applied to the case where the iso-seismic line was close to a circle, it was superior to similar formulas used internationally because the parameters it contained varied from place to place and could be calculated.

During the first 5-year economic plan, the Chinese government suggested that some important projects in the earth- 


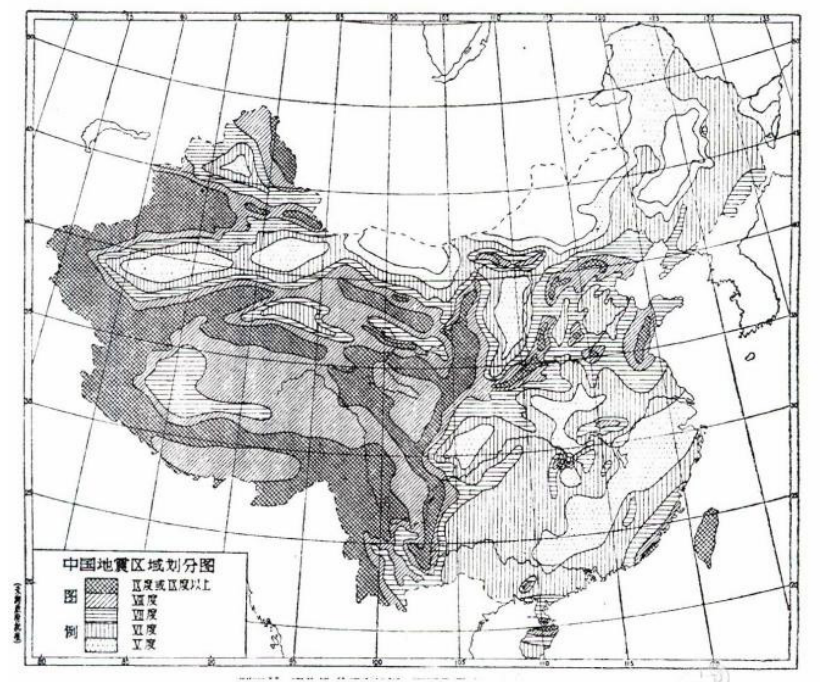

1957 年版中国讪震比妙

Figure 7. The 1957 version of the national earthquake zoning map for China. (Source: Institute of Geophysics, China Earthquake Administration.)

quake zone required seismic fortification. In particular, the 156 construction projects aided by the former Soviet Union had to have local basic intensity data. In 1954, under the guidance of Russian consultant R. N. Gorshkov, IGCAS' Shanbang Li led researchers who analyzed the rich historical data and carried out field geological surveys and mapping to compile China's national earthquake zoning map (Fig. 7; Li, 1957). The basic principles used in the compilation of maps were that earthquakes that have occurred in history may be repeated, and under the same geological conditions, earthquakes of the same intensity may occur.

This was China's first national earthquake zoning map. However, it has always been controversial. Even the main plotter Shanbang Li believed that "at present, the earthquake science has not found the correct theoretical basis for predicting the characteristics, intensity, and time of earthquakes, so at the current level, only such earthquake regions can be compiled. The division map is used to indicate the general situation of seismic activity, and its accuracy and predictability are not enough" (Li, 1957). Later, it was not used by Chinese industries (Guo, 2014).

Closely combining the development of seismological science with construction and production was a major characteristic of IGCAS. At the start of 1951, IGCAS constructed seismic stations in the PRC (Zhuang and Yan, 2007). From 1957 to 1958,12 basic seismic stations, such as Beijing and Lhasa, were built successfully. Through these networks, China monitored earthquakes with a magnitude of 4 or above in most areas of the country. These basic observational data have been used successfully in the international exchange, which placed China's earthquake work at the forefront of the world.
The institute also organized basic seismology studies and published the Chronological Table of Earthquake Data of China (Historical group of seismological Committee, 1956), which laid the foundation for studying seismic activity in China (Fu, 1990). They also published Seismic Catalogue of East China (Center for Analysis and Prediction, State Seismological Bureau, 1970) and China Seismic Intensity Scale (China Earthquake Working Group, 1971), which provided valuable data for long-term seismological research.

\subsubsection{Application oriented basic research in meteorology}

The progress in atmospheric dynamics was also very important. In the 1950s, systematic research on atmospheric circulation in East Asia and the monsoon climate and cold waves was enhanced, which significantly improved the degree of accuracy in the forecasting of dangerous weather - and weather in general. In atmospheric physics, cloud physics tests and artificial precipitation research were cultivated. Small- to medium-scale dynamics and atmospheric exploration research were developed.

In the late 1950s, Xiuji Zhou first proposed the concept that the accumulation caused by turbulent motion in clouds accelerated development of water droplets of different scales and their growth. Using the stochastic process and random function theory to systematically investigate the various factors that affected the formation of precipitation in clouds, such as water vapor, airflow, water content, and charged electricity, Zhou formed a new theory called the warm cloud precipitation fluctuation theory. Thus, the limitation of the original precipitation process theory broke down, and his representative work "Research on the microphysics mechanism of warm cloud precipitation" reached the international level (Song, 2005).

In 1963, Zhou was responsible for the creation of Chinese atmospheric optics. He explored the mutual constraints of lightning and precipitation, the thundercloud lightning mechanism and its impact methods, and the electromagnetic radiation effects of lightning and thunderclouds. The research on lightning physics that he completed, and the thundercloud comprehensive detection system he and technicians developed jointly played an important role in bringing the achievements of modern scientific and technological means and mathematical physics into atmospheric physics (Song, 2005).

Since then, Chinese scientists solved the basic theoretical problems of atmospheric remote sensing, and Qingcun Zeng wrote the first monograph in the world on the quantitative theory of satellite remote sensing. The concept and method of the best information layer proposed by Zeng was an extremely important means for monitoring corresponding disasters such as rainstorms and typhoons. His inversion algorithm for solving the remote sensing equation became the 
main algorithm for the main satellite data processing and service centers in the world (Editorial office, 2020).

\subsubsection{Geomagnetic and geophysical research}

In 1953, to act in concert with the urgent needs of economic development and national defense, China's first geomagnetic map (1950) was compiled (Y. F. Chen, 2007) to provide highquality service to telecommunications departments.

IGCAS also initially cooperated with the Institute of Post and Telecommunications and the Department of Physics of Wuhan University to study the ionosphere and to preside over the preparations for building an ionosphere observation station (H. E. Chen, 2007).

During the Cultural Revolution, earthquake and geomagnetic work was sustained due to practical needs and the support of the CCCPC. Entrusted by the People's Liberation Army command, on 23 January 1969, CAS issued the National Geomagnetic Survey mission (code 3912) to IGCAS for research in aviation, nautical sciences, earthquakes, and space and for the exploration of minerals, oil, and gas. This decision promoted the development of geomagnetism and other disciplines and provided opportunities for future international cooperation with the UK and Russia in geomagnetism (An, 2007).

Large-scale field surveys were typical of physical prospecting. During the same period, IGCAS participated in the geophysical scientific investigation of Qinghai and Tibet organized by CAS from 1975 to 1978, studied the uplift and deep structures of the Tibetan Plateau (Lai, 2007), and established four seismic stations (Linzhi, Yadong, Chayu, and Biru; Song, 2007).

\subsection{The key basic research related to national defense}

To even consider the recapture of Taiwan and the establishment of the People's Liberation Army (PLA) navy, there was an urgent need to study wave prediction (Guan, 2006). To break the technical blockade of Western countries and to improve the accuracy of wave and typhoon prediction in China (Yang, 2007), Jeou-jang Jaw established the wave research group (later the wave research laboratory) in 1953. Jeou-jang Jaw was inspired by Walter Heinrich Munk's (1947) theory of forecasting a storm path based on the first wave of the surge in order to forecast the actual position of the storm center and its moving path (Guan, 2006). In the early 1950s, IGCAS cooperated with the Institute of Applied Physics, Institute of Electronics, Changchun Institute of Applied Chemistry, CAS, and the navy to develop a set of wave observation and analysis instruments. IGCAS cooperated with the navy to establish a wave observation station in Qingdao and obtained materials from Europe for marine environment prediction (Shi and Liu, 1989), which also provided a scientific basis for marine operation and construction of coastal defenses (Wen, 1985).
During the 1950-1970s, the "two bombs and one star" (atomic bombs, missiles, and artificial satellites) project was China's most important major scientific engineering project, similar to the Manhattan Project in the United States. Only scientists with a good political background and a high level of scientific research had the opportunity to participate. Some scientists in the field of geophysics were also involved, and they carried out important applied fundamental research on related missions. During the 1960-1970s, entrusted by the National Defense Science and Technology Commission, IGCAS participated in the seismic observation of multiple nuclear explosion tests and the "National underground nuclear test seismic reconnaissance speed" report, which improved the level of seismic observation and promoted research in focal physics (Wang et al., 1990).

In the early 1960s, the United States and the former Soviet Union resumed the development of their respective strategic anti-missile systems. The IGCAS magnetic storm research group of the Earth Institute undertook the 6405 mission, which focused on the physical phenomenon of missile reentry into the atmosphere; this group was also responsible for the space environment and its interaction with missiles. First, they conducted a theoretical study of the interaction between high-speed missiles and plasma and a simulation experiment on the physical process of the interaction between the missile entering the ionosphere and ionospheric plasma. Second, they researched the impact of high-speed missiles on the propagation of radio waves and conducted theoretical and experimental research on the excitation of plasma waves during the flight (Jeou-jang Jaw biography Compilation Group, 2005 , p. 91). After nearly a year of research, a special report on "Anti-missile defense and missile phenomenology" was completed. Due to the impact of the Cultural Revolution, this work did not continue.

In late 1959, the United States and the former Soviet Union again competed for high-altitude nuclear experiments. To understand the electromagnetic pulse killing range of high-altitude nuclear explosions, IGCAS carried out research on the generation and propagation mechanism of electromagnetic pulses of high-altitude nuclear explosions; a comprehensive analysis of the interaction process between nuclear explosions and the upper atmosphere and the geomagnetic field qualitatively explained the generation of various electromagnetic pulses. The mechanism laid the academic foundation for the application of magnetic fluid wave research and established the basic mode of electromagnetic pulse propagation in the upper atmosphere and the geomagnetic field.

Dong Fang Hong I was one of the earliest artificial satellites in the world to carry out space radiation environment simulation experiments. In June 1967, CAS established the Dong Fang Hong I satellite radiation ring module, and Zhenxing Liu was responsible for providing the radiation ring mode indicators of particle flux, energy spectrum, and radiation dose in the radiation zone (Jeou-jang Jaw biography 
Compilation Group, 2005, p. 86). In the difficult environment of the Cultural Revolution, everyone started by collecting detection results, drawing simple charts for scientific papers, using their knowledge of theoretical research on the laws of movement of charged particles in the magnetic field, and using simple tools such as slide rules and hand-cranked computers. The data collection and collation of electrons, protons, and cosmic ray particles in the inner and outer radiation zones and the synchronous orbit area were completed, which provided a basis for the space radiation environment for the next design and development of satellites (Yang, 2004).

These missions often brought together the top geophysical science and technology elites. At that time, due to confidentiality, they could not publish papers publicly. Instead, they provided information to the task executor in the form of internal reports or papers. But the key basic research of these national defense missions has become an intangible knowledge reserve, and to some extent, this precious local knowledge based, on China's special regional landscape, provided a reserve of information for the development of geophysics.

\section{Conclusion and some reflections}

Too many political activities have interfered with the normal order of scientific research activity in China. Activities such as the Great Leap Forward violated the laws of scientific research itself. Even international academic exchanges have been greatly influenced by politics, and the continuous and steady development of geophysics has been interrupted. In 1961, the Academy of Sciences issued the "14 points for science" to return scientific research to the right track and to ensure the working hours of scientists. But later, IGCAS became fragmented, and a unified pattern of geophysical disciplines was broken, weakening the research strength of Chinese geophysics. The Cultural Revolution that began in 1966 brought China's society, which included the scientific and technological community, into a state of collapse.

Very quickly, with the expansion of the fields of research in geophysics, CAS decided to divide IGCAS into four institutes in February 1966 (Qu, 2007). The Cultural Revolution had a severe impact on IGCAS and the development of the related discipline of geophysics. On 17 March 1967, the CCCPC decided to implement military control over satellite development institutes. Jeou-jang Jaw, who was the victim of false or unjust charges, committed suicide because he could not bear the persecution of the Cultural Revolution. The 651 Satellite Design Institute and the Institute of Applied Geophysics of CAS were all transferred to the National Defense Science and Technology Commission (China Academy of Space Technology, 2009). On 24 April 1970, China's first artificial satellite, Dong Fang Hong I, launched successfully.

From 1949 to 1966, China's economic progress was stalled, domestic political movements continued, and its scientific and technological foundations were weak. Especially in the context of the Cold War, scientific and technological exchanges with the United States and Western Europe were interrupted.

From the perspective of social history, based on the development of IGCAS during this period, this paper outlines the roadmap outlined at that stage of geophysics development to reflect the influence of the academic development of a core scientific research institution under specific social, political, and economic conditions. The key scientific output of typical Chinese scientists in geophysics at that stage eventually led to the significant achievements in geophysics in China today.

In short, the development of geophysics in China from 1949 to 1966 experienced a process that started with the introduction of advanced scientific and technological knowledge by scientists who had returned from abroad and who then gradually adapted to China's special political and economic environment by seeking a space for academic development under complex and difficult conditions. At that point, IGCAS, which gathered the elite talent of Chinese geophysics, devoted significant energy to the cultivation of talent and an organizational structure (which included the layout of research rooms, etc.). IGCAS tried to obtain policy support from CAS and its Institute of Geophysics to promote the specialization of geophysics in China. It also strived to enhance scientific and technological capacity, and it devoted a considerable amount of research time to the construction of seismic stations, the accumulation of the latest observational data, and the analysis of historical data. The above work can be regarded as the construction of the scientific and technological infrastructure in a broad sense, which laid the foundation for the development of geophysics in China.

After returning home, Chinese scientists gradually took root in a land of backward scientific, technological, and economic conditions and political unrest under the leadership of the Communist Party of China. They were transformed from scientists who studied basic theories to personnel or engineers who applied basic science. They had to change their research focus to the application of basic research that was closely related to national needs, which included the applied basic research that was closely related to national defense, industrial production, and life. After returning to China, Chinese scientists such as Jeou-jang Jaw and Zhenchao Gu, who had made outstanding achievements during their studies abroad, actively explored new fields such as artificial rainfall and numerical weather forecasting. The significance of these type of works was not only to solve the urgent task of industrial and agricultural production but also to fill in the academic gap in related fields in China.

From the source of knowledge production, geophysics knowledge was first introduced from the knowledge of these returning scientists. These talented scientists in the 1930s and 1940s were well trained at several first-class universities in Western, developed countries, and they made significant achievements in geophysics under the guidance of famous tutors of geophysics. Later, scientists took the practical 
work, such as artificial rainfall, which was closely related to industrial and agricultural production, as an important field of knowledge production, and they promoted the application of basic research, such as cloud physics. At the same time, Chengyi Fu and other scientists used the regional geophysical conditions, such as the Tibetan Plateau and East Asian atmospheric circulation, as their unique knowledge factories and accomplished world-class academic achievements. After the Cultural Revolution ended in 1976, China's scientific and technological circles returned to international academic exchanges. Through academic journals, conferences, and overseas visits, China's scientific and technological circles gained necessary data and knowledge, and their academic horizons broadened. Chengyi Fu and others paid attention to important global issues, such as global climate change.

In other words, it was a wise move for scientists to promote the development of disciplines in a special environment. When CAS forged the relationship between theoretical research and the development of academic disciplines in the early days, it put forward the slogan of "missions lead disciplines; disciplines promote missions". Starting from the 1950 s, the vast majority of the scientific research issues of the institute were proposed based on the real needs of the state. In theory, many new and practical scientific problems were put forward to the discipline in the framework of the mission, which promoted the development of the discipline and completed the application of missions delivered by the state. In fact, under the social environment of serious political interference in scientific research, it was difficult to study basic theory that seemed to have no value in application, so scientists hoped that, in the framework of "missions drive disciplines", the mission was the means and discipline was the goal (Jaw, 1968).

Judging from the published papers as the results of knowledge production, there were not many world-class scientific research achievements made by Chinese people during this period. Shiyan Tao, Tu-cheng Yeh, and others made great achievements in the study of East Asian monsoon and atmospheric circulation and the meteorology of Tibetan Plateau that were based on the conditions in China when China's scientific and technological circles were basically isolated from the outside world. In particular, in 1957, papers by Shiyan Tao, Tu-cheng Yeh, Zhenchao Gu, and three other papers on atmospheric circulation in East Asia were published in the famous Swedish journal Tellus in stages, which allowed global meteorological science to understand the achievements of China's meteorological science. However, only a limited number of Chinese scientific and technological experts were exceptional enough to attain international recognition. Most other Chinese scientists did not achieve any world-class academic achievements before going back to China.

However, scientific research should follow the law of development. For decades, it had been difficult to maintain a balance between scientific development and serving the state's economic plan. In that special era of advocating "missions drive disciplines", many geophysicists who were engaged in basic research were forced to spend significant time on industrial practice, and the basic theoretical research related to geophysics lacked stable, long-term support. Pure theoretical research was relatively ignored.

At this stage, Chinese scientific and technological circles repeated the process from social unrest to the restoration of order, and the development of geophysics sought opportunities to survive in the cracks of the political movement. This situation did not change until 1978, after the reform and opening up policy. As Chengyi Fu stated, "Scientific development must first obey the needs of production and construction, but it should also take into account its development; otherwise, haste does not bring success" (the Editing Committee of the Geophysical Society, 1989), and then the long-term, robust development of the discipline could be accomplished.

Data availability. No data sets were used in this article.

Author contributions. $\mathrm{ZZ}$ conceived and designed the whole study, wrote the paper, and was in charge of its continuous revision. RW searched for and provided part of the research literature and arranged and reorganized the references. All authors read and approved the paper.

Competing interests. The authors declare that they have no conflict of interest.

Special issue statement. This article is part of the special issue "History of geophysical institutes and observatories". It is not associated to a conference.

Acknowledgements. The authors appreciate the anonymous reviewers, for their valuable comments on this article, and the editor's modification and embellishment. We thank Thomas A. Gavin for the English copy-editing in this paper.

Financial support. This research has been supported by the Talent Project of the Youth Innovation Promotion Association of the Chinese Academy of Sciences (grant no. Y722011) and the "History of Science and Technology in the New China" at the Institute for the History of Natural Sciences (grant no. Y921021).

Review statement. This paper was edited by Kusumita Arora and reviewed by two anonymous referees. 


\section{References}

An, Z. C.: The "3912" Mission and Research on the Geomagnetic Field, in: A Glorious Journey - 60 Years of the Chinese Geophysical Society, edited by: Chinese Geophysical Society, Seismological Press, Beijing, China, 337-340, 2007 (in Chinese).

Center for analysis and prediction, State Seismological Bureau: Catalogue of earthquakes in eastern China (1970-1979), Seismological Press, 1970 (in Chinese).

Chao, J. P.: In Remembrance of Jeou-jang Jaw, in: A Glorious Journey - 60 Years of the Chinese Geophysical Society, edited by: Chinese Geophysical Society, Seismological Press, Beijing, China, 101, 2007 (in Chinese).

Chen, H. E.: Pioneer of Contemporary Chinese Geophysics - Jeoujang Jaw, International Earthquake Dynamics (Recent Developments in World Seismology), 1, 20-23, 1992a (in Chinese).

Chen, H. E.: T. C. Yeh: A Pioneer of Contemporary Geophysics in China, International Seismology, 9, 23-25, 1992b (in Chinese).

Chen, H. E.: Groundbreaking Contributions of the First Generation of Geophysicists in China, in: A Glorious Journey - 60 Years of the Chinese Geophysical Society, edited by: Chinese Geophysical Society, Seismological Press, Beijing, China, 284-285, 2007 (in Chinese).

Chen, J.: Zhao Jiuzhang and China's aerospace industry, Jiangsu Science and technology information, 11, 20-21, 2003 (in Chinese).

Chen, Y. F.: In Remembrance of Zongqi Chen, in: A Glorious Journey - 60 Years of the Chinese Geophysical Society, edited by: Chinese Geophysical Society, Seismological Press, Beijing, China, 87, 2007 (in Chinese).

Chen, Y. T.: One of the Founders of the Chinese Geophysical Society - Outstanding Geophysicist Chengyi Fu, in: A Glorious Journey - 60 Years of the Chinese Geophysical Society, edited by: Chinese Geophysical Society, Seismological Press, Beijing, China, 122, 2007 (in Chinese).

Chen, Y. W.: A study on the upper atmosphere model, Acta Geophysics, 1, 1-11, 1963 (in Chinese).

Chen, Y. W.: Vertical dynamic transport and its influence in the middle and thermosphere, Acta Geophysics, 4, 353-367, 1980 (in Chinese).

China Academy of Space Technology: Streetlights in the Sky Legends of China's Satellites and Spacecraft, China Astronautic Publishing House, Beijing, China, 21, 2009 (in Chinese).

China Earthquake working group: China earthquake catalogue, Science Press, 1971 (in Chinese).

Chinese Geophysical Society: History of the Discipline of Geophysics in China, China Science and Technology Press, Beijing, p. 70, p. 85, 2012 (in Chinese).

Chinese Meteorological Society: Compendium of Historical Materials of Chinese Meteorological Society, Meteorological Press, Beijing, China, 31, 2002 (in Chinese).

Chinese Society of Oceanology and Limnology: Deep Mourning for Professor Hanli Mao, Chin. J. Oceanol. Limn., 4, 297-299, 1989 (in Chinese).

Editorial office: Qingcun Zeng: thousands of kinds of weather reflect the red heart, Invention and innovation (big technology), 2, 23-25, 2020 (in Chinese)
Fan, H. Y. (Ed.): The Complete Works of Zhu Kezhen, Vol. 16, Shanghai Science and Technology Education Press, Shanghai, China, 233, 2009 (in Chinese).

Fang, H. H. and Zhang, Z. H.: Jeou-jang Jaw and Department of Geophysics in USTC - an interview with the researcher Lizeng Zhao, Physics Bulletin, 12, 113, 2012 (in Chinese).

Fortieth Anniversary Editing Committee of the Institute of Geophysics: Forty Years of the Institute of Geophysics, 1950-1990, Seismological Press, Beijing, China, 2, 1990 (in Chinese).

$\mathrm{Fu}, \mathrm{C}$. Y.: Several issues regarding earthquake prediction, Science Bulletin, 3, 30-36, 1963 (in Chinese).

Fu, C. Y.: Review and Prospect of IGCAS, Proceedings of the 40th Anniversary Celebration of the IGCAS, Beijing, edited by: Chinese Society for Rock Mechanics and Engineering, Seismological Press, Beijing, China, 4, 10, 1990 (in Chinese).

Fu, C. Y., Chen, Y. T., and Chen, Y.: Research on Seismic Physics in China, J. Geophys., 4, 315-320, 1979 (in Chinese).

Gao, M. Q. and Hu, Z. Y.: Rescuing the historical data of Sheshan magnetostatic and the establishment of the database, Proceedings of the ninth annual meeting of China geophysical society, Changsha, China, October 1993, 275, 1993 (in Chinese).

Gu, Z. C.: Dynamic influence of Tibetan Plateau on East Asian circulation and its importance, Science of China, 3, 283-303, 1951 (in Chinese).

Guan, B. X.: In Deep Remembrance of Jeou-jang Jaw, a Wellknown Oceanographer, Pioneer and Founder of Scientific Research on Sea Waves in China, Advances in Marine Science, 3, 277, 2006 (in Chinese).

Guo, A. N.: The history of China's first-generation earthquake intensity zoning map, Casual Reading World, 2, 185-191, 2014 (in Chinese).

Historical group of seismological Committee: Chronological Table of Earthquake Data of China, Chinese Academy of Sciences, Science Press, 1956.

$\mathrm{Hu}, \mathrm{X}$. W.: The First Meteorologist of New China (II), Journal of Guizhou Meteorology, 2, 48-49, 1994 (in Chinese).

Institute of Geophysics, Chinese Academy of Sciences: To Jeoujang Jaw, Director of the IGCAS, Archives of the Institute of Geophysics, Chinese Academy of Sciences, File No.: Z376-89002-17, 1958 (in Chinese).

Institute of Geophysics, Chinese Academy of Sciences: Request to consider again whether to participate in Japan international numerical forecast conference, Archives of the Chinese Academy of Sciences, File No.: z376-145-003, 30 May 1960, 16-20, 1960.

Jaw, J. J.: Zur Thermodynamik der Passat-grundstrmung. Veröffentlichungen des Meteorologischen Instituts der Universität Berlin, Band II, Heft 6, 5-24, 1937.

Jaw, J.-j.: Report of the Delegation's Visit to the Soviet Union for Geophysics, Archives of the Chinese Academy of Sciences, File No.: A004-177-001, 7 January 1953, 1-25, 1953a (in Chinese).

Jaw, J.-j.: Soviet Geophysical Research Work I Have Seen, People's Daily, 11 July 1953, 3, 1953b (in Chinese).

Jaw, J.-j.: General Lines and the Work of the Institute of Geophysics, Science Bulletin, 8, 37-42, 1954 (in Chinese).

Jaw, J.-j.: Opening Speech at the First Membership Congress of the Chinese Geophysical Society, Acta Geophysica Sinica, 1, 1-8, 1957a (in Chinese). 
Jaw, J.-j.: Western Pacific Regional Conference in Tokyo for the International Geophysical Year, Science Bulletin, 10, 312-313, 1957b (in Chinese).

Jaw, J.-j.: The Soviet Artificial Satellite Is a Lucky Star Rising in Cosmic Space, Physics Bulletin, 11, 642, 1957c (in Chinese).

Jaw, J.-j.: Progress of Meteorological Research in China in the Past Decade, Acta Meteorologica Sinica, 3, 206-211, 1959 (in Chinese).

Jaw, J.-j.: The progress of solar wind, outer space magnetic field, and detection of low-energy charged particles, Science Bulletin, 11, 9-19, 1963 (in Chinese).

Jaw, J.-j.: Scientific research and organization work that I have done, 19 September 1968, collected by: Jeou-jang Jaw, Archives Office of National Center for space science, Chinese Academy of Sciences, 1968 (in Chinese).

Jaw, J.-j., Xu, R. L., and Zhou, G. C.: The moving region of charged particles in the dipole magnetic field and its model experiment, Science Bulletin, 11, 56-57, 1963 (in Chinese).

Jeou-jang Jaw biography Compilation Group: Biography of Jeoujang Jaw, Guizhou People's Publishing House, Guizhou, China, 86-91, 2005 (in Chinese).

Jiang, T. H.: The policy of running the Academy in history, Sci. News, 6, 26-27, 2015.

Lai, M. H.: Recollections of Scientific Investigation in Qinghai and Tibet, in: A Glorious Journey - 60th Anniversary Special Issue of Reviewing the Chinese Geophysical Societ, edited by: Chinese Geophysical Society, Seismological Press, Beijing, China, 409411, 2007 (in Chinese).

$\mathrm{Li}, \mathrm{S}$. B.: The problem of regional intensity division of seismic activity, Science Bulletin, 12, 66-68, 1953 (in Chinese).

Li, S. B.: Map of China's seismic area division and its description (I), General description, J. Geophys., 2, 127-158, 1957 (in Chinese).

Liaison Office of the Chinese Academy of Sciences: Discuss again the reply to Japan and it is not suitable to participate in the International Conference on numerical prediction, Archives of the Chinese Academy of Sciences, File No.: z376-145-004, 7 June 1960, 21, 1960 (in Chinese).

Liu, C. R.: Creation of a Great Cause, No Regret in Pursuit Commemorating the 50th Anniversary of the International Geophysical Year, and Remembrance of Zongqi Chen, Founder of the Institute of Geophysics, in: A Glorious Journey - 60th Anniversary Special Issue of Reviewing the Chinese Geophysical Society, edited by: Chinese Geophysical Society, Seismological Press, Beijing, China, 238-239, 2007 (in Chinese).

Liu, Z. X.: Jeou-jang Jaw, the Founder of Space Physics in China, in: A Glorious Journey - 60th Anniversary Special Issue of Reviewing the Chinese Geophysical Society, edited by: Chinese Geophysical Society, Seismological Press, Beijing, China, 139, 2007 (in Chinese).

Qian, J.: The first Congress of Chinese Geophysical Society and the founding meeting of Academic Committee of Institute of Geophysics, Chinese Academy of Sciences, Chinese Journal of Geophysics, 1, 153-154, 1957 (in Chinese).

Qu, K. X.: Feelings and Inspiration, in: A Glorious Journey 60 Years of the Chinese Geophysical Society, edited by: Chinese Geophysical Society, Seismological Press, Beijing, China, 503, 2007 (in Chinese).
Riehl, H. and Yeh, T. C.: The intensity of the net meridional circulation, Q. J. Roy. Meteor. Soc., 76, 182-188, 1950.

Secretariat of the Central Office of Administration of Academia Sinica: Initial Draft on the History of Academia Sinica, 375, 1988.

Shi, Z. K. and Liu, A. G.: A Generation of Great Masters, Models for Scholars - Cherishing the Memory of Professor Chongben He, a Well-known Chinese Marine Educator and the First Chief Editor of Our School's Journal, Journal of Ocean University of China (Natural Science Edition), 4, 1-5, 1989 (in Chinese).

Song, C. T.: Anecdotes of Entering Tibet Twice, in: A Glorious Journey - 60th Anniversary Special Issue of Reviewing the Chinese Geophysical Society, edited by: Chinese Geophysical Society, Seismological Press, Beijing, China, 373, 2007 (in Chinese).

Song, L. Z.: The elite of famous schools Tsinghua University Peking University, Jinghua Publishing House, Beijing, China, 131-132, 2005 (in Chinese).

Sun, Y.: T. C. Yeh: Founder of Qinghai-Tibet Plateau Meteorology, Dialectics of Nature, 34, 104, 2012 (in Chinese).

The Editing Committee of the Geophysical Society: Progress in Geophysics in China in the 1980s - Commemorating the 80th Birthday of Professor Chengyi Fu, Academic Publishing House, Beijing, China, 1989 (in Chinese).

Tsinghua School History Committee: Tsinghua, the Land of Woods and Waters with Stars Shining Brightly in the Clear Sky, Tsinghua University Press, Beijing, China, 77, 2001 (in Chinese).

Wang, G. F., Xiong, S. B., Hao, W. C., Yin, Z. X., Ren, J. R., Li, Y. M., Shao, A. M., and Sun, K. Z.: Seismic Observation and Seismic Detection of Nuclear Explosions - A Historical Review of the Two Major Military Industry Missions Borne by the IGCAS, Proceedings of Academic Conference at the 40th Anniversary of the Institute of Geophysics, 1950-1990, Seismological Press, Beijing, China, 4, 1990 (in Chinese).

Wen, S. C.: Several Points of View on the Development of Wave Measuring Instruments, Marine Technology, 2, 1-3, 1985 (in Chinese).

White, R. M.: The role of mountains in the angular-momentum balance of the atmosphere, J. Meteorol., 6, 353-355, 1949.

$\mathrm{Wu}, \mathrm{H} .:$ The delegation of the Chinese Academy of Sciences visited the Soviet Union for the first time, Information and Research of Academy History, 2, 18, 1991 (in Chinese).

Wu, J. P.: 20th Century Chinese Academic Dictionary: Surveying and Mapping, Atmospheric Science, Solid Geophysics, Applied Geophysics, Marine Science, Fujian Education Press, Fuzhou, China, 63, 86, 2002 (in Chinese).

Xie, Y. S.: New Chinese seismic intensity table, Acta geophysics Sinica, 1, 35-47, 1957 (in Chinese).

Xie, Y. S.: Contributions of Jeou-jang Jaw to the Development of Chinese Seismological Science, Recent Developments in World Seismology, 8, 12-13, 2007 (in Chinese).

$\mathrm{Xu}$, R. L.: Memories of working with Jeou-jang Jaw, Hongye Fan eds., Historical data and research of the Chinese Academy of Sciences, 6, 10-11, 1992 (in Chinese).

$\mathrm{Xu}, \mathrm{R}$. L. and Jaw, J.-j.: Changes of the Sturm Capture Area during Geomagnetic Disturbance, J. Geophys., 1, 12-21, 1962 (in Chinese).

Yang, J. W.: Jeou-jang Jaw Initiated Sea Wave Research in China, Science Times, available at: http://news.sciencenet.cn/ 
sbhtmlnews/2007101603045380191701.html?id=191701 (last access: 21 June 2020), 2007 (in Chinese).

Yang, L. Y.: National Day 55: "National Defense Situation" surging in Beijing, Workers Daily, 12 October 2004 (in Chinese).

Yeh, T.-c.: On energy dispersion in the atmosphere, J. Meteorol., 6, $1-16,1949$.

Yeh, T.-c.: On the general circulation over Eastern Asia (II) (III), Tellus, 10, 3, 1958.

Yeh, T.-c.: Selected works of Yeh T. C., Anhui Education Press, Anhui, China, 2-4, 2008 (in Chinese).

Yeh, T.-c. and Zhu, B.: Some Basic Problems of Atmospheric Circulation, Science Press, Beijing, China, 1963 (in Chinese).

Yeh, T.-c. and Li, M. C.: Adaptation of wind and pressure fields in small and medium scale motion, Acta Meteorologica Sinica, 4, 409-423, 1964 (in Chinese).

Yeh, T.-c., Zhou, J. B., and Ji, L. R.: People Who Achieved Great Merits for the Development of the Geophysical Sciences in China - Commemorating Jeou-jang Jaw and Comrade Yiqing Wei, in: A Glorious Journey - 60 Years of the Chinese Geophysical Society, edited by: Chinese Geophysical Society, Seismological Press, Beijing, China, 136-137, 2007 (in Chinese).

Zhang, S. and Yin, X. D.: Swedish physicist Hannes Alvin's visit to China in 1963, Review of science and culture, 02, 58-75, 2019 (in Chinese).
Zhou, J. P.: International Geophysical Year and the Construction and Development of China's Geomagnetic Stations, in: A Glorious Journey - 60 Years of the Chinese Geophysical Society, edited by: Chinese Geophysical Society, Seismological Press, Beijing, China, 437-439, 2007 (in Chinese).

Zhu, G. K.: The International Polar Year (IPY) and the International Geophysical Year (IGY), in: A Glorious Journey - 60 Years of the Chinese Geophysical Society, edited by: Chinese Geophysical Society, Seismological Press, Beijing, China, 433, 2007a (in Chinese).

Zhu, G. K.: Reminiscing Zongqi Chen's past, in: A Glorious Journey - 60 Years of the Chinese Geophysical Society, edited by: Chinese Geophysical Society, Seismological Press, Beijing, China, 253-255, 2007b (in Chinese).

Zhuang, C. T. and Yan, X. Y.: A Review of the Development of the Network of Seismic Stations in China, in: A Glorious Journey 60 Years of the Chinese Geophysical Society, edited by: Chinese Geophysical Society, Seismological Press, Beijing, China, 408411, 2007 (in Chinese). 